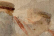

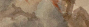

Fis.

Mos:

(1)

ars $\rightarrow$

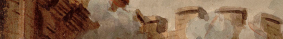

WDithe te is
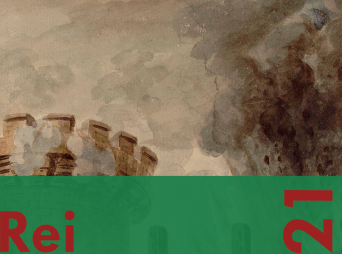

Revista digital de Historia

y Didáctica de la Historia 
Revista anual

Fecha de inicio: 1995

RevistaPantaRei.pantarei@um.es

\section{Edita:}

Centro de Estudios del Próximo Oriente y la

Antigüedad Tardía - CEPOAT

Edificio Universitario Saavedra Fajardo.

Universidad de Murcia

C/ Actor Isidoro Máiquez, 9

30007 - MURCIA - ESPAÑA

Teléfono: $(+34) 868883890$

cepoat@um.es

Web: https://revistas.um.es/pantarei

\section{Ediciones de la Universidad de Murcia - EDITUM}

Edificio Pleiades. Campus de Espinardo.

Universidad de Murcia

C/ Campus, s/n

30100 - MURCIA - ESPAÑA

Teléfono: (+34) 868883013

editum@um.es

Web: https://www.um.es/web/editum/

En portada: Prise de la Bastille. Biblioteca Nacional de Francia (BNF).

Edición 2021

ISSNe: 2386-8864

ISSN: $1136-2464$

Depósito legal: MU-966-1995

Responsables de los textos: sus autores.

Responsable de la presente edición: Consejo Editorial de Panta Rei. 


\section{CONSEJO DE REDACCIÓN}

Coordinador editorial

Egea Vivancos, Alejandro [Didáctica de la Historia, Universidad de Murcia]

Secretaria

Arias Ferrer, Laura [Didáctica de la Historia, Universidad de Murcia]

Editores

Bellatti, Ilaria [Didáctica de la Historia, Universidad de Barcelona]

Jiménez Vialás, Helena [Historia Antigua, Universidad de Murcia]

Martínez Gil, Tània [Didáctica de Historia,

Universidad de Barcelona]

Meseguer Gil, Antonio José [Historiador, Profesor de Secundaria]

Ortiz García, Jónatan [Arqueología, Universidad de Alcalá de Henares]

Romero Molero, Alberto [Arqueología, Universidad Isabel I]

Sáez Giménez, David Omar [Historiador, Profesor de Secundaria]

Sáez Rosenkranz, Isidora V. [Didáctica de la Historia, Universidad de Barcelona]

Sánchez Mondejar, Celso Miguel [Arqueólogo,

Patrimonio Inteligente]

Responsables de traducción y corrección lingüística

Martínez Martínez, Cristina [Profesora de Secundaria, Sociedad Española de Lenguas Modernas] Albaladejo Albaladejo, Sara [ISEN-Universidad de Murcia]

\section{CONSEJO ASESOR}

Adroher Auroux, Andrés María [Arqueología, Universidad de Granada]

Albero Muñoz, $M^{a}$ del Mar $\left[H{ }^{a}\right.$ del Arte, Universidad de Murcia]

Alia Miranda, Francisco [Historia Contemporánea, UCLM]

Arciniega García, Luis [Historia del Arte, Universidad de Valencia]

Barrio Barrio, Juan Antonio [Historia Medieval,

Universidad de Alicante]

Castellano i Solé, Núria [Egiptología, Schola

Didàctica Activa S.L.]

Chapman, Arthur [History Education, University

College of London, Reino Unido]

Chavarria Arnau, Alejandra [Arqueología, Università di Padova, Italia]

Cid López, Rosa María [Historia Antigua, Universidad de Oviedo]

Cobacho López, Ángel [Derecho, Universidad de Murcia]

Cuenca López, José María [Didáctica de la Historia, Universidad de Huelva]

Egea Bruno, Pedro M. ${ }^{a}$ [Historia Contemporánea, Universidad de Murcia]
Feijoo Martínez, Santiago [Arqueología, Consorcio

Ciudad Monumental de Mérida]

García Atienzar, Gabriel [Prehistoria, Universidad de

Alicante]

Ginestí Rosell, Anna [Filología Clásica, Katholische

Universität Eichstätt-Ingolstadt]

González Monfort, Neus [Didáctica de la

Historia, Universidad Autónoma de Barcelona]

González Soutelo, Silvia [Arqueología, Universidad

Autónoma de Madrid]

Haber Uriarte, María [Prehistoria, Universidad de

Murcia]

Hernández de la Fuente, David [Filología Clásica,

Universidad Complutense]

Hutson, Scott R. [Anthropology, University of Kentucky, EEUU]

lgual Luis, David [Historia Medieval, UCLM]

Irigoyen López, Antonio [Historia Moderna,

Universidad de Murcia]

Jover Maestre, Francisco Javier [Prehistoria,

Universidad de Alicante]

Mahony, Simon [Digital Humanities, University College

of London, Reino Unido]

Marsilla de Pascual, Francisco Reyes [Técnicas

historiográficas, Universidad de Murcia]

Martínez-Burgos García, Palma [H. ${ }^{a}$ del Arte, UCLM]

Mathis, Christian [Didaktik der Geschichte, PH Zürich]

Miralles Maldonado, José Carlos [Filología Clásica,

Universidad de Murcia]

Molina Gómez, José Antonio [Historia Antigua,

Universidad de Murcia]

Mónica Ghirardi [Historia Moderna, Universidad

Nacional de Córdoba, Argentina]

Navarro Espinach, Germán [Historia Medieval,

Universidad de Zaragoza]

Ni Cassaithe, Caitriona [Didáctica de la Historia,

Dublin City University, Irlanda]

Noguera Celdrán, José Miguel [Arqueología,

Universidad de Murcia]

Ortiz Heras, Manuel [Historia Contemporánea, UCLM]

Panzram, Sabine [Historia Antigua, Universität

Hamburg]

Pérez Molina, Miquel Emilio [Filología Clásica,

Universidad de Murcia]

Pinto, Helena [Didáctica de la Historia, CITCEM

University of Porto, Portugal]

Prados Martínez, Fernando [Arqueología,

Universidad de Alicante]

Sánchez lbáñez, Raquel [Didáctica de la Historia, Universidad de Murcia]

Sancho Gómez, Miguel Pablo [Educación, UCAM]

Victoria Moreno, Diego [Historia Contemporánea, UNED]

Vilar García, María José [Historia Contemporánea,

Universidad de Murcia]

Vivas Sainz, Inmaculada [H. ${ }^{a}$ del Arte, UNED]

Zamora López, José Ángel [Próximo Oriente Antiguo, CCHS-CSIC] 



\section{Índice}

\section{Artículos}

Libelos, camarillas y banquetes: una propuesta para reconstruir las proclamaciones militares en la 7 Antigüedad Tardía a través de los casos de Probo, Magnencio y Juliano

Miguel Pablo Sancho Gómez

El uso de los videojuegos para la enseñanza de la Historia Antigua en Educación Secundaria: una investigación educativa

Manuel Jesús Jaldón-Méndez Sánchez

'What did it achieve?' - Students' conceptions about the significance of the French Revolution

Christian Mathis

Pervivencia e influencia de los mitos fundacionales del franquismo en los textos escolares de la enseñanza secundaria castellanoleonesa

Sergio Ibáñez Llorente y Almudena Alonso-Centeno

La enseñanza y aprendizaje de las Ciencias Sociales a través del patrimonio, videojuegos y emociones. 103 Estudio de caso en un IES de Huelva (España)

Rocío Jiménez-Palacios y José María Cuenca López

Desarrollo de la conciencia histórica. Una propuesta de intervención y evaluación para la Educación de Adultos

Héctor López-Bajo, Rosendo Martínez Rodríguez y María Sánchez-Agustí

Concepciones de docentes en formación suecos y españoles sobre la desigualdad de género en perspectiva temporal

Jorge Ortuño Molina y Fredrik Alvén

Narrativa y significación histórica en la comunicación de los museos nacionales canadienses en Facebook

Iñaki Navarro-Neri, Pilar Rivero, Borja Aso y Ana Mendioroz-Lacambra

\section{Entrevista}

Haciendo historia para el bien común. Entrevista a Linda S. Levstik

Laura Arias Ferrer y Alejandro Egea Vivancos

\section{Reseñas}

M. Sartre (2021), Le Bateau de Palmyre. Quand les mondes anciens se rencontraient (Vle siècle av. J.- 239

C./Vle siècle ap. J.-C.), Paris: Éditions Tallandier

Juan Álvarez García

Janire Castrillo, Las mujeres vascas durante la Baja Edad Media. Vida familiar, capacidades jurídicas, 245 roles sociales y trabajo, Madrid, Sílex Universidad, 2020

Iratxe Gillate

M. Ortiz Heras (coord.). (Manual de) Historia de España (siglo XX). Del desastre del 98 a la crisis 249 sistémica actual, Albacete: Altabán, 418 págs. ISBN: 978-84-15252-46-7

Herminio Lebrero Izquierdo 



\title{
Desarrollo de la conciencia histórica. Una propuesta de intervención y evaluación para la Educación de Adultos
}

\section{Development of historical consciousness. A practical teaching experience and evaluation proposal for Adult Education}

\author{
Héctor López-Bajo \\ CEPA Distrito Centro (Madrid) \\ hectorbajo22@hotmail.com \\ iD $\underline{0000-0002-8833-8545}$
}

\author{
Rosendo Martínez Rodríguez \\ Universidad de Valladolid \\ rosendo.martinez@uva.es \\ D 0000-0003-3816-0432
}

\author{
María Sánchez-Agustí \\ Universidad de Valladolid \\ maria.sanchez.agusti@uva.es \\ 0000-0000-17163-3276
}

Recibido: 08/12/2020

Aceptado: 17/03/2021

\section{Resumen}

En esta investigación abordamos una cuestión fundamental de la enseñanza de la historia como es el desarrollo de la conciencia histórica ligada al pensamiento histórico. Para ello, se ha elaborado una conceptualización exhaustiva de las competencias de la conciencia y el pensamiento histórico, con el objetivo de evaluar su progreso en un grupo de diecisiete estudiantes que cursan la asignatura de historia en la Educación de Adultos. La evaluación se ha realizado a partir de una propuesta didáctica diseñada a tal efecto e implementada a lo largo del curso académico 2019-2020. Los resultados muestran que, a través de la metodología aplicada, basada en actividades de indagación e interpretación histórica, los estudiantes pueden mejorar sus niveles de conciencia y pensamiento histórico. Además, se comprueba que, a pesar de tratarse de dos ámbitos diferenciados del conocimiento, ambos grupos competenciales progresan de manera paralela y complementaria.

\section{Palabras clave}

Enseñanza de la historia, educación de adultos, conciencia histórica, método de enseñanza, educación ciudadana.

\begin{abstract}
The development of historical consciousness linked to historical thought, a fundamental issue in the teaching of history, is addressed in this research. To carry it out, an exhaustive conceptualization of the competences of consciousness and historical thought has been developed, with the aim of evaluating their progress in a group of seventeen history students in Adult Education. The evaluation has been made from a didactic proposal designed for this purpose and implemented throughout the 2019-2020 academic year. The results show that, through the applied methodology, based on historical inquiry and interpretation activities, students can improve their levels of consciousness and historical thinking. In addition, it is found that, despite being two different aspects of historical knowledge, both competence groups progress in a parallel and complementary way.
\end{abstract}

\section{Keywords}

History education, historical consciousness, adult education, methods teachers, citizenship education.

Para citar este artículo: López-Bajo, H., Martínez-Rodríguez, R., y Sánchez-Agustí, M. (2021). Desarrollo de la conciencia histórica. Una propuesta de intervención y evaluación para la Educación de Adultos. Panta Rei: revista digital de Historia y didáctica de la Historia, 135-159. doi: 10.6018/pantarei.459241 


\section{Introducción}

La historia, junto con la memoria, son dos pilares fundamentales de cualquier comunidad. El modo en que una sociedad mira y analiza su pasado nos da pistas irrefutables de su forma de organización social y política, de su configuración identitaria y de su carácter plural o excluyente. La aparición de la historia científica y, a remolque de ésta, la lenta evolución de su enseñanza, han marcado de algún modo el camino de nuestras sociedades democráticas, que deberían poner ahora su énfasis educativo en la construcción de una ciudadanía crítica, que mira al pasado con afán indagatorio y no como mera justificación intencionada de su presente. Esta es una función ideal de la historia que, en el contexto de polarización y exaltación que vivimos en la actualidad, se hace más necesaria que nunca.

Es este afán por hacer de la historia una disciplina crítica el que nos mueve, como docentes y como investigadores, a encontrar un corpus teórico de aprendizajes históricos que sirvan a ese objetivo: el de una enseñanza de la historia que no se quede en la repetición del relato, sino que se adentre en las más profundas aguas del pensamiento y la conciencia. En este sentido, son muchos los trabajos que vienen construyendo las bases conceptuales de lo que se ha venido a llamar pensamiento histórico y, en una línea paralela, conciencia histórica. La conciencia histórica, menos estructurada en sus proposiciones que el pensamiento histórico, en cierto modo es (o puede ser) efecto de este, pero también de otra serie de condicionantes sociales que configuran nuestra comprensión y asimilación de un pasado común, como la memoria, la cultura histórica y la historia pública. La importancia de la conciencia histórica, por lo tanto, es fundamental por este carácter conclusivo de nuestra experiencia histórica, por ser el modus operandi de nuestra racionalidad temporal e histórica. De manera que su desarrollo, idealmente ligado al del pensamiento histórico, no puede quedar ajeno al ámbito educativo y a nuestra intencionalidad didáctica.

Sin embargo, no son muchos los trabajos que han experimentado y evaluado en la práctica el desarrollo de la conciencia histórica. Posiblemente, por la dificultad que supone la elaboración, no ya de una propuesta que permita su desarrollo, sino, particularmente, de una conceptualización que defina sus parámetros y evalúe su progreso. Este ha sido el propósito de la presente investigación, elaborar una conceptualización de la conciencia y el pensamiento histórico y evaluar su desarrollo a través de la puesta en práctica de una propuesta didáctica pensada a tal efecto. Y se ha hecho, además, bajo la premisa inicial de que, aun tratándose de competencias diferenciadas, pensamiento histórico y conciencia histórica pueden tener un desarrollo paralelo y complementario.

Entendemos también que, tanto el pensamiento histórico como la conciencia histórica, no tienen por qué limitarse a un periodo formativo, sino que su desarrollo forma parte de nuestro aprendizaje a lo largo de la vida. Por ello, la Educación de Adultos, mucho menos abordada desde la investigación (Belando-Montoro, Barros y Lampreia, 2020), nos ofrece un novedoso campo de estudio, igual de válido y particularmente oportuno. Oportuno porque, siguiendo los parámetros de la andragogía, el adulto necesita encontrar sentido a los aprendizajes antes de abordarlos y, de alguna manera, su éxito consiste en el valor práctico y real de lo que aprende. 


\section{Marco Teórico}

\subsection{Conceptualización de la conciencia histórica}

El concepto de conciencia histórica tiene su origen en la filosofía, antes que en la historia o en la educación, iniciándose un nuevo discurso histórico elaborado a partir de la concepción histórica moderna y el nacimiento de la historicidad, como nuevas guías para relacionarnos con nuestro pasado colectivo. Así, se articula una conciencia temporal intrínseca del ser humano que se moviliza en un presente histórico, ligado moralmente a hechos colectivos del pasado, pero que marca distancia con él, porque lo entiende diferenciado. Se permite, de esta manera, comprender una multiplicidad de puntos de vista relativos (Gadamer, 2003) y, en proyección, una concepción temporal repleta de posibilidad e incertidumbre hacia el futuro (Koselleck, 1993). Posibilita además el desarrollo de una concienciación moral que ayude a la toma de decisiones y acciones transformadoras del presente que, a su vez, son constructoras del futuro (Freire, 2015).

El nacimiento de la historicidad del hombre moderno será un factor clave para el cambio de mentalidad en la relación del ser humano con su pasado social y un estímulo sustancial, como señala Koselleck (1993), en la configuración del concepto de conciencia histórica. Su germen lo sitúa en el contexto del pensamiento ilustrado en el siglo XVIII, cuando señala que "se puede mostrar que la elaboración del singular colectivo 'historia' es un proceso semántico que alumbra nuestra experiencia moderna" (p. 127). Este alumbramiento contemporáneo de la historicidad, considerado "como una de las grandes revoluciones de nuestro tiempo" (Gadamer, 2003, p. 41), construye conceptos que vertebran la relación pasado-presente, como el concepto de experiencia que produce la autoconciencia de un presente histórico (Dilthey, 1978) ० bien la idea de formar parte de singulares colectivos en una historia universal. Dichos conceptos conducen a una nueva relación del ser humano con su pasado social, comprendiendo que, por un lado, con nuestra experiencia somos seres dentro de la historia, piezas en el engranaje de sus continuidades $y$, por otro, que aceptamos el cambio y, con él, los diferentes puntos de vista en el pasado y la incertidumbre para el futuro. Una incertidumbre que no lo será tanto porque, paralelamente, irá consolidándose el ideal de progreso (su germen será en el siglo XVII, si bien se consolidará en el XVIII), que marcará en la historia una percepción de desarrollo ascendente clave en la mentalidad contemporánea (Bury, 2009).

A partir de la tradición filosófica, Jhon Rüsen, en la década de los 70 del siglo XX, relacionará conciencia y funcionalidad social, convirtiéndose en uno de los referentes teóricos de un enfoque educativo para el concepto, con influencia y aplicación empírica en el área geográfica francogermana. Para este autor, en la conciencia histórica "el tiempo se hace inteligible y adquiere sentido convirtiéndose en Historia", provocando que de una forma cognoscible "teja pasado y presente y futuro" con la finalidad de orientar la experiencia cotidiana (Rüsen, 2008, p. 2).

En un plano individual, la conciencia histórica se desarrolla a partir de la memoria, la identidad - las expectativas que vamos construyendo desde el nacimiento de nuestra conciencia temporal individual y social. Estas operaciones influyen en la manera que comprendemos nuestro mundo, nos aportan identidad individual que, desde un sentido cartesiano, configura un concepto de estabilidad y continuidad del yo (res cogito) frente a los cambios temporales y superficiales de la realidad externa y de nosotros mismos. Por otro lado, también nos ofrecen vínculos con identidades colectivas (familia, club de futbol, nación...) gracias a la memoria viva (Ricoeur, 
2010) y a los horizontes de experiencia y expectativa que, como señala Koselleck (1993), entrecruzan pasado y futuro en una proyección ideal, como puede ser la idea de progreso que nos hace avanzar y conjugar nuestros proyectos individuales con los colectivos.

\subsection{Finalidad social de la conciencia histórica: marco teórico para una enseñanza crítica y funcional de la historia en la educación de adultos}

La educación formal de adultos, debido a su origen ligado al mercado de trabajo y a estar muy condicionada por las demandas de éste, ha naturalizado e incorporado de forma sustancial el carácter instrumental y práctico a sus enseñanzas (Jarvis, 2010). Malcom Knowles, pionero de una pedagogía diferenciada para las personas adultas, conocida como andragogía, parte del presupuesto de que el adulto necesita saber por qué debe aprender algo y cómo puede utilizarlo en su vida real antes de emprender el aprendizaje (Knowles 1995, como se citó en SánchezDomenech, 2015). Por tanto, la motivación del adulto en su aprendizaje depende de su percepción sobre si el conocimiento a aprender le va a ayudar a hacer frente a problemas o situaciones que se le presentarán en la vida real o bien le será útil para sus retos y objetivos personales. En este sentido, cualquier enfoque didáctico de las áreas del conocimiento en adultos, si quieren contar con ese estímulo motivacional, deben tener en cuenta el ámbito experiencial del adulto donde se fusiona aprendizaje y vida real. Como señala Mezirow (1991), el aprendizaje del adulto requiere de la experiencia previa, pero necesita transformarla con un significado nuevo que parta de la reflexión y compromiso sobre el propio aprendizaje. De esta manera, el ámbito experiencial se convierte en el epicentro de la propia enseñanza andragógica, ya sea para desarrollar metodologías didácticas motivadoras o incluso como patrón para categorizar a los discentes en estadios de aprendizaje, según procedan a utilizar y transformar su experiencia en conocimiento (Kolb, 1984 y 2017).

En la actualidad, la educación de adultos, además de las funciones institucionales curriculares que le aportan su condición formal (titulación de enseñanzas oficiales) y su carácter instrumental propio de su idiosincrasia como educación no obligatoria, también ha cobrado un importante sentido social, encuadrado en paradigmas socioeducativos como la educación permanente o la educación a lo largo de la vida. Estos conceptos nacen en la década de los 70 del siglo XX en el marco de instituciones supranacionales (UNESCO, Consejo de Europa, la OCDE y el Club de Roma) y en el contexto de una educación de adultos muy necesaria para la alfabetización en plena reconversión industrial (Fernández, 2000). No obstante, en las primeras décadas del siglo XXI, se irán transformando en pilares de todo el sistema educativo para los nuevos modelos socioeconómicos posindustriales de la economía y sociedad del conocimiento.

Estas características (instrumental, experiencial y social) intrínsecas a la educación de adultos, no se pueden ignorar a la hora de construir una propuesta de enseñanza y aprendizaje de la Historia y de las Ciencias Sociales. Sin duda, necesita un enfoque que haga significativos estos conocimientos al alumnado para que valore como oportunidad educativa sus singularidades. Por ejemplo, el potencial de la experiencia y de la cultura histórica en el adulto que, obviamente, aunque solo sea por edad y vivencias, es mayor que en los niños y adolescentes. También en la línea andragógica de Knowles, los alumnos deben percibir que los conocimientos históricos y sociales los hacen más competentes para sus retos sociolaborales o personales del presente. 
Esta relación entre los objetivos de la enseñanza, la percepción de los alumnos y las competencias sociolaborales de nuestro sistema nos lleva a preguntarnos sobre la función del conocimiento social e histórico para la educación de un ciudadano en el siglo XXI. A modo de síntesis, e inspirándonos en tres enfoques diferentes, podemos categorizar tres objetivos, en el marco de una educación de adultos.

Primeramente, el desarrollo de un conocimiento crítico a partir del tratamiento y gestión de la información, como requisito fundamental para ejercer una ciudadanía democrática. Este enfoque está muy presente en los documentos institucionales ${ }^{1}$ y en la didáctica disciplinar histórica, en la que se pone en valor los procedimientos de investigación del historiador como metodología extrapolable para el desarrollo de competencias de ciudadanía crítica (Martínez-Rodríguez y Sánchez-Agustí, 2018).

En segundo lugar, la comprensión del presente histórico, desde el conocimiento de un pasado significativo, sus cambios y sus continuidades en tiempo largo, con la finalidad de ampliar las alternativas y posibilidades de la realidad para imaginar futuros posibles. Esta función, que refleja el potencial prospectivo de la ciencia histórica, frecuente en la historiografía más reciente (Pagès, 2019), es planteada como una de las claves para que la historia vuelva a ser una ciencia social referente para el presente.

Finalmente, la disminución de las brechas de diferente naturaleza (digitales, competencias en lectoescritura, de género y socioeconómicas), un enfoque prioritario en la formación permanente, teorizada por la Unesco para reducir las desigualdades sociales y las de acceso a la información, muy frecuentes en la educación de adultos ${ }^{2}$. Las Ciencias Sociales, por su naturaleza, fomentan la comunicación y el conocimiento socializador que permiten construir significados a partir de las competencias más instrumentales, ayudando a los alumnos adultos a dar sentido a los conocimientos.

En este contexto, en dónde el conocimiento social e histórico ayuda al alumnado adulto a tomar conciencia de sí mismo y de su realidad social y a intervenir en el presente (Freire, 2015), el enfoque competencial aportado por la conciencia histórica puede ofrecer un gran potencial, y convertirse en un marco teórico para una propuesta didáctica. Su valor didáctico, en nuestra opinión, puede ser transformador para conectar el conocimiento disciplinar con la vida y experiencia del adulto $y$, de esta manera, ser liberador en los términos freirianos de conciencia crítica. Esto es así, debido a que, como hemos visto en su conceptualización, conjuga un pensamiento histórico no formal, donde entran en juego las operaciones propias de la memoria, la identidad y la experiencia, con un pensamiento histórico formal, que debe ser aprehendido, pues no es de carácter natural o intuitivo (Wineburg, 2001), y ejerce una función orientadora hacia la vida práctica en su relación con las necesidades culturales de las actividades humanas (Rüsen, 2008).

\footnotetext{
${ }^{1}$ Recomendación del Consejo de la Unión Europea de 22 de mayo de 2018, relativa a las competencias clave para el aprendizaje permanente.

https://eur-lex.europa.eu/legal-content/ES/TXT/PDF/?uri=CELEX:32018H0604(01)\&from=EN

OCDE (2009). Habilidades y competencias del siglo XXI para los aprendices del nuevo milenio en los países de la OCDE. Education Working Papers, 41, 1-17.

2 Recomendación sobre el aprendizaje y la educación de adultos aprobada por la Conferencia General de la UNESCO en su $38^{a}$ reunión, en noviembre de 2015 https://unesdoc.unesco.org/ark:/48223/pf0000245179 spa
} 


\section{Metodología}

\subsection{Objetivo general de la investigación}

El objetivo de este trabajo es analizar de forma cualitativa y empírica, a través de una propuesta educativa, las relaciones de progreso, interacción e interdependencia entre competencias de conciencia histórica y de pensamiento histórico en un alumnado adulto, que estudia en un centro oficial para obtener el título de Graduado en Secundaria. De las relaciones entre ambas categorías, definidas teóricamente en un doble marco de competencias e indicadores, nos interesa mostrar los vínculos de progreso y desarrollo entre ambas, observando si existe, o no, un progreso de las competencias de conciencia histórica hacia niveles complejos y críticos (nivel III en las tablas 1,2 y 3) en alumnos que hayan adquirido durante el curso competencias de pensamiento histórico (nivel II-III en la Tabla 4). En esta categoría amplia de progreso interrelacionado caben otras variables que tendremos en cuenta en la investigación y que se formulan a priori como indicadores de observación y análisis cualitativo.

En alumnos que no demuestren un desarrollo competencial de pensamiento histórico durante el curso (inferior al nivel III en la Tabla 4), analizaremos cuál ha sido su nivel competencial de conciencia histórica al final del mismo, y si, alguno de ellos, ha alcanzado un nivel "de conciencia crítica" (nivel III en las tablas 1, 2 y 3 ) y de qué manera. También se analizarán qué sesgos de conocimiento histórico han predominado en sus trabajos.

En alumnos que hayan adquirido competencias de pensamiento histórico durante el curso (nivel IIIII en la Tabla 4), nos preguntamos si estos alumnos han progresado en competencias de conciencia histórica y de qué manera se observa esta mejoría desde sus niveles iniciales al comienzo del curso.

Para ejemplificar estas variables, hemos realizado una categorización de los alumnos dividiéndolos en cuatro grupos según su capacitación o progreso competencial: Grupo 1, alumnos que han demostrado un desarrollo o alta capacitación de pensamiento y de conciencia histórica; Grupo 2, alumnos que han progresado desde niveles más bajos a superiores en ambas competencias de pensamiento y conciencia histórica; Grupo 3, alumnos que han progresado en pensamiento histórico, pero no en conciencia histórica; Grupo 4, alumnos que no han progresado en ambas competencias a lo largo del curso.

\subsection{Diseño de un marco de progreso competencial de la conciencia histórica y el pensamiento histórico en personas adultas}

Con el fin de poder evaluar los niveles de conciencia histórica y pensamiento histórico de los estudiantes durante la intervención didáctica, hemos diseñado un marco de competencias en personas adultas, que plasmamos en cuatro rúbricas.

En el caso de la conciencia histórica, que constituye el interés principal de este trabajo, nos inspiramos en tres modelos teóricos de progreso: el modelo de narrativas de Rüsen (2008), el modelo didáctico de Duquette $(2011$; 2015) y el modelo socio-estructural de Pandel (citado en Kölbl y Konrad, 2015); que han fundamentado otras investigaciones de aplicación educativa (Barca, 2013; Kölbl y Straub, 2001; Miguel-Revilla y Sánchez-Agustí, 2018a). 
En primer lugar, partimos de la base de que el desarrollo de una conciencia histórica no necesariamente implica pensamiento crítico. Por tanto, en nuestro modelo, los tratamos como dos realidades diferentes. En este sentido, tenemos en consideración una conciencia histórica que puede ser compleja y crítica, o simple y estereotipada (Duquette, 2011 ; 2015) y, aun así, cumple su función como orientadora de la vida práctica en el presente y en la previsión del futuro. Para el modelo teórico de desarrollo competencial definimos una conciencia histórica no crítica (no reflejada) a partir de unos indicadores que demuestran que el alumno cae en sesgos de pensamiento histórico (Carretero y Montanero, 2008) en las relaciones explicativas entre las dimensiones temporales pasado, presente y futuro. En segundo lugar, como indica el consenso de diferentes autores (Duquette, 2015; Seixas, 2017), se puede desarrollar una conciencia histórica crítica a partir de un proceso de reflexión, toma de distancia y objetivación, trabajando las competencias de pensamiento histórico.

Para nuestro modelo nos inspiraremos en las subcompetencias narrativas propuestas por Rüsen, que permiten dar sentido al pasado y orientar el presente (Rüsen, 2008): la experiencia, ligada al contenido de la narración, que tiene que ver con la percepción/concepción de la dimensión temporal del pasado, diferenciándola del presente; la interpretación, relacionada con la forma de la narración, que se define como la percepción/conciencia de la dimensión temporal del presente en su relación holística con las otras dimensiones, pasado y futuro; y la orientación, fundamentada en la función narrativa, que es resultado de las otras dos para orientar la vida práctica hacia el futuro.

A continuación, relacionamos estas tres competencias con las capacidades, destrezas y operaciones cognitivas asociadas al pensamiento temporal e histórico. Así, la primera de ellas, la experiencia, se manifiesta en utilizar el pasado en la explicación de sucesos del presente: relaciones causales y explicativas entre pasado y presente; y también en diferenciar pasado y presente. La segunda, la interpretación, se proyecta en la capacidad para analizar y explicar causalmente el presente histórico dentro de escalas temporales más amplias o estructuras de tiempo medio y largo. Y la tercera, la orientación, consiste en orientar decisiones éticas teniendo en cuenta el cambio histórico, así como prever escenarios futuros posibles.

A su vez, estas competencias de la conciencia histórica requieren de un plan de nivelación para definir un modelo de adquisición. Este modelo de progresión en la adquisición, que presentamos en al Tabla 1, 2 y 3 tiene su fundamentación teórica en los trabajos de Rüsen (2008) y Duquette $(2011$; 2015) ya señalados, permitiendo establecer tres niveles de progresión en la conciencia histórica. Los tres niveles, con sus respectivos indicadores, son: Nivel 1, de conciencia "no reflejada", mediado por las narrativas maestras y la cultura histórica y caracterizado por el predominio de sesgos de comprensión histórica y temporal; Nivel 2, de transición, definido por una atenuación de los sesgos de comprensión histórica y un progreso hacia niveles de la etapa siguiente; y Nivel 3, de conciencia histórica crítica, que conjuga los indicadores de conciencia del "nivel narrativo" de Duquette y del "nivel genealógico" de Rüsen.

Como se puede apreciar en las tablas, los tres niveles de progreso de la conciencia histórica se aplican a la evaluación de cada una de las competencias presentadas anteriormente: experiencia (Tabla 1), interpretación (Tabla 2) y orientación (Tabla 3). 


\section{Tabla 1}

\section{Niveles de progreso en la competencia sobre la experiencia}

$1 .{ }^{\circ}$ Competencia sobre la experiencia: Concepción y uso del pasado como dimensión temporal diferente del presente (utilización del pasado en la explicación de acontecimientos presentes)

\section{NIVEL I. CONCIENCIA "NO REFLEJADA" NIVEL II. TRANSICIÓN}

1.1.

Ahistoricismo/presentismo/anacronismo: irrelevancia e infravaloración del pasado para explicar el presente o bien distorsión significativa del pasado desde los parámetros del presente.

\subsection{Pasado estático/irrelevancia del} cambio histórico: no hay diferenciación entre pasado y presente, no se identifican cambios ni inflexiones en un pasado continuo: concepción del presente a partir de un pasado inmutable.

\subsection{Objetivación y simplismo} monocausal: concepción de un pasado objetivado, estereotipado o excesivamente ejemplarificado (pasado ejemplar 0 ideal)
Valoración

cualitativa

relativa a la

atenuación de

los sesgos del

Nivel I o bien

en el avance de

complejidad propio del

Nivel III.
NIVEL III. CONCIENCIA HISTÓRICA CRÍTICA

1.1. Valoración de la relevancia e importancia del pasado para explicar el presente

\subsection{Se diferencia e identifica} contextualmente cambios y continuidades en el pasado y en su relación con el presente

Fuente: elaboración propia

Tabla 2

Niveles de progreso en la competencia sobre la interpretación

$2 .^{\circ}$ Competencia sobre la interpretación: Explicación del presente histórico, en síntesis temporal con el pasado, dentro de escalas temporales más amplias o coyunturas de tiempo medio y estructuras de tiempo largo

$\begin{array}{ll}\text { NIVEL I. CONCIENCIA "NO REFLEJADA” } & \text { NIVEL II. } \\ & \text { TRANSICIÓN }\end{array}$

2.1.

Ahistoricismo/presentismo/anacronismo: visión autosuficiente del presente desvinculado del pasado

2.2. Irrelevancia del cambio histórico: no se identifican cambios ni continuidades que den resultado a un presente histórico; no se integra el presente en otras escalas temporales más amplias (tiempo medio coyuntural o tiempo largo estructural)
Valoración cualitativa relativa a la atenuación de los sesgos del Nivel I o bien en el avance de complejidad propio del Nivel III.
NIVEL III. CONCIENCIA HISTÓRICA CRÍTICA

2.1. Valoración de un presente histórico: resultado de un pasado complejo

2.2. Se diferencia e identifica los cambios y continuidades y se incluye al presente histórico dentro de otras escalas temporales más amplias (tiempo medio coyuntural o tiempo largo estructural) 
2.3. Objetivación y simplismo monocausal: relación explicativa simplista o estereotipada entre pasado y presente; explicación determinista pasado-presente
2.3. Relación explicativa compleja entre el pasado y presente: multicausal, valoración interpretativa y subjetiva de las relaciones causales

Fuente: elaboración propia

\section{Tabla 3}

Niveles de progreso en la competencia sobre orientación

$3 .^{\circ}$ Competencia sobre orientación: Prever escenarios futuros posibles teniendo en cuenta el cambio histórico y la orientación de decisiones prácticas y valoraciones éticas

\begin{tabular}{|c|c|c|}
\hline NIVEL I. CONCIENCIA “NO REFLEJADA” & $\begin{array}{l}\text { NIVEL II. } \\
\text { TRANSICIÓN }\end{array}$ & NIVEL III. CONCIENCIA HISTÓRICA CRÍTICA \\
\hline $\begin{array}{l}3.1 \text {. } \\
\text { Ahistoricismo/presentismo/anacronismo } \\
\text { No se identifica un futuro diferente al } \\
\text { presente }\end{array}$ & $\begin{array}{l}\text { Valoración } \\
\text { cualitativa } \\
\text { relativa a la } \\
\text { atenuación de } \\
\text { los sesgos del }\end{array}$ & $\begin{array}{l}\text { 3.1. Valoración de un futuro complejo y } \\
\text { abierto relacionado con las otras } \\
\text { dimensiones temporales }\end{array}$ \\
\hline $\begin{array}{l}\text { 3.2. Irrelevancia del cambio histórico } \\
\text { No se tienen en cuenta los cambios y } \\
\text { continuidades del pasado-presente para } \\
\text { prever un escenario futuro posible o bien }\end{array}$ & $\begin{array}{l}\text { Nivel I o bien } \\
\text { en el avance } \\
\text { de } \\
\text { complejidad } \\
\text { propio del }\end{array}$ & $\begin{array}{l}\text { 3.2. Se tiene en cuenta los cambios y } \\
\text { continuidades del pasado-presente para } \\
\text { prever un escenario futuro posible y } \\
\text { vinculado a procesos histórico }\end{array}$ \\
\hline $\begin{array}{l}\text { se prevé desvinculado del presente } \\
\text { histórico }\end{array}$ & Nivel III. & $\begin{array}{l}\text {-Se tiene en cuenta el cambio histórico para } \\
\text { orientar decisiones prácticas y valoraciones } \\
\text { éticas }\end{array}$ \\
\hline
\end{tabular}

histórico para orientar decisiones

prácticas y valoraciones éticas

\subsection{Objetivación y simplismo monocausal (evolución histórica)}

Relaciones explicativas simplificadas y estereotipadas entre pasado, presente y futuro que explican evolución histórica; o bien explicaciones deterministas sobre el progreso

-No se contempla cambios negativos, crisis

-No se contempla alternativas de progreso

\author{
aloración \\ atenuación de \\ en el avance \\ de \\ complejidad \\ propio de \\ Nivel III.
}

\subsection{Relación explicativa compleja entre el pasado, presente y futuro que explique evolución histórica:}

- Se contemplan futuros abiertos de crisis y progreso

- Se contemplan alternativas con base histórica de futuros posibles, probables

Fuente: elaboración propia

Por lo que respecta al análisis del pensamiento histórico, se ha elaborado también una tabla de desarrollo competencial (Tabla 4). En su construcción teórica hemos utilizado como referentes conceptuales una selección de los metaconceptos teorizados por Seixas y Morton (2013): uso de evidencias de fuentes primarias; identificación de cambio y continuidad y análisis de causa y consecuencia. A la hora de su aplicación a una propuesta de aula los hemos desarrollado, 
respetando sus principios conceptuales, junto con indicadores de valoración de capacidades de pensamiento histórico de elaboración propia, incidiendo en aquellos que trabajen la dimensión temporal e inspirados en trabajos de Braudel (1970), Domínguez (2015), y Santisteban (2010). Por último, la rúbrica elaborada requiere de tres niveles de progresión competencial: nivel I, sin adquisición competencial o bien muy limitada; nivel II, adquisición con suficiencia competencial; y nivel III, adquisición compleja competencial, demostrando operaciones cognitivas de deducción, inferencia o extrapolación.

Tabla 4

Niveles de progreso en las competencias de pensamiento histórico

\begin{tabular}{|c|c|c|c|}
\hline $\begin{array}{l}\text { Metaconceptos } \\
\text { (Seixas y } \\
\text { Morton 2013) }\end{array}$ & $\begin{array}{l}\text { NIVEL I } \\
\text { Sin adquisición } \\
\text { competencial o bien muy } \\
\text { limitada }\end{array}$ & $\begin{array}{l}\text { NIVEL II } \\
\text { Adquisición con suficiencia } \\
\text { competencial }\end{array}$ & $\begin{array}{l}\text { NIVEL III } \\
\text { Adquisición compleja } \\
\text { competencial }\end{array}$ \\
\hline $\begin{array}{l}\text { 1. Uso de } \\
\text { evidencias de } \\
\text { fuentes } \\
\text { primarias }\end{array}$ & $\begin{array}{l}\text { 1.1 El alumno comprende } \\
\text { el concepto de fuente, } \\
\text { pero no las cuestiona. } \\
\text { - Si la información es } \\
\text { creíble (no detecta } \\
\text { anacronismos) } \\
\text {-La falsedad o veracidad } \\
\text { de la propia fuente } \\
\text {-Los } \\
\text { intereses/tendenciosidad } \\
\text { detrás de la propia } \\
\text { fuente } \\
\text {-La utilidad de la fuente } \\
\text { /información para su } \\
\text { trabajo } \\
\text { 1.2 El alumno no } \\
\text { comprende la información } \\
\text { de la fuente y no es } \\
\text { capaz de contextualizarla }\end{array}$ & $\begin{array}{l}\text { 1.1 El alumno cuestiona de } \\
\text { forma limitada las fuentes } \\
\text { (no todos los puntos) } \\
\text {-Si la información es } \\
\text { creíble (detecta } \\
\text { anacronismos) } \\
\text {-La falsedad o veracidad } \\
\text { de la propia fuente } \\
\text {-El interés/tendenciosidad } \\
\text { detrás de la propia fuente } \\
\text { - La utilidad de la fuente } \\
\text { /información para su } \\
\text { trabajo } \\
\text { 1.2 El alumno explica y } \\
\text { valora la información } \\
\text { relevante en relación con } \\
\text { el objeto de estudio } \\
\text { (contexto histórico). }\end{array}$ & $\begin{array}{l}\text { 1.2 El alumno explica, valora } \\
\text { y contextualiza la } \\
\text { información relevante de la } \\
\text { fuente y es capaz de inferir y } \\
\text { deducir información nueva }\end{array}$ \\
\hline $\begin{array}{l}\text { 2. Identificar } \\
\text { cambio y } \\
\text { continuidad }\end{array}$ & $\begin{array}{l}2.1 \text { El alumno no identifica } \\
\text { ni describe lo que cambia } \\
\text { ni lo que permanece }\end{array}$ & $\begin{array}{l}2.1 \text { Explicación simple de } \\
\text { lo que cambia o lo que } \\
\text { permanece con } \\
\text { perspectiva histórica y } \\
\text { temporal }\end{array}$ & $\begin{array}{l}2.1 \text { Explicación compleja y } \\
\text { relacionada del cambio con } \\
\text { perspectiva histórica: uso de } \\
\text { conceptos, teorías e } \\
\text { inferencias. }\end{array}$ \\
\hline $\begin{array}{l}\text { 3. Analizar } \\
\text { causa y } \\
\text { consecuencia }\end{array}$ & $\begin{array}{l}\text { 3.1 Descripción de } \\
\text { intenciones y motivaciones } \\
\text { sin explicación } \\
3.2 \\
\text { Identificación/descripción } \\
\text { de causas, pero sin } \\
\text { relaciones con efectos y }\end{array}$ & $\begin{array}{l}\text { 3.1 Explicación } \\
\text { intencionada: } \\
\text { argumentación simple y } \\
\text { contextualizada } \\
3.2 \text { Identificación causa - } \\
\text { efecto-consecuencia y } \\
\text { explicación simple y } \\
\text { contextualizada. }\end{array}$ & $\begin{array}{l}\text { 3.1 Explicación intencionada: } \\
\text { explicación compleja, con } \\
\text { inferencia (uso de conceptos } \\
\text { y teorías explicativas } \\
3.2 \text { Explicación causal } \\
\text { compleja: } \\
\text { conexiones/relaciones efectos } \\
\text { y consecuencias; inferencia, }\end{array}$ \\
\hline
\end{tabular}


consecuencias (sin

contextualizar bien).

3.3 No se valora la relevancia de las causas en los hechos

3.4 El alumno no explica el tiempo largo ni lo relaciona con el tiempo corto (si es capaz de identificarlo)

\subsection{Valoración relevancia causas \\ 3.4 El alumno identifica y explica el tiempo largo y es capaz de relacionarlo con el tiempo corto.}

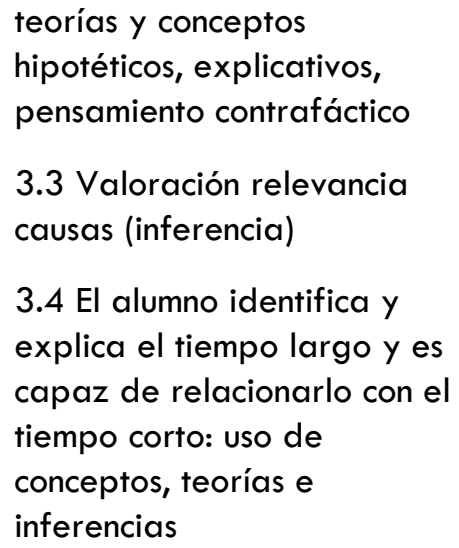

Fuente: elaboración propia

\subsection{Tipo de investigación y muestra}

La metodología de investigación empleada para analizar estas variables es de tipo cualitativo, propia del estudio de caso, haciendo uso también de algunos criterios de cuantificación, sobre una muestra de 17 alumnos. Los participantes son todos mayores de edad, pertenecientes a grupos que cursaron las enseñanzas oficiales para la obtención del título de Graduado en Educación Secundaria para población adulta en el curso 2019-20.

El estudio de caso se realiza en la educación formal, en una dinámica curricular normal de un centro de adultos público, centro de referencia situado en Madrid, llamado CEPA Distrito Centro. Su localización geográfica y las características socioculturales del entorno hacen que la diversidad sea el rasgo de identidad principal del alumnado. Esta diversidad es una de las singularidades propias de la idiosincrasia de los centros de adultos que, en muchos casos, son crisoles de diferentes edades y culturas que construyen estructuras peculiares de socialización (Jarvis, 2010). En este sentido, la muestra para la investigación debía recoger esta diversidad, y para ello se aplicó un muestreo estructural, con el fin de alcanzar un punto de saturación máximo en las variables socioculturales del alumnado adulto que asiste presencialmente a una educación formal y reglada de los CEPAS (Bizquerra, 2014). Para el muestreo estructural se han tenido en cuenta las siguientes variables:

- Edad: hemos utilizado como categorías tres tramos de edad que están relacionados con las teorías del ciclo vital del desarrollo del adulto de Levinson (1986): preadultez (de 18 a 22), adultez temprana (de 22 a 45 ) y adultez media (de 45 a 60 ).

- Situación sociolaboral: diferenciamos entre población pasiva y población activa (distinguiendo entre empleados y desempleados).

- Ámbito cultural y lengua materna: hispano hablante con lengua materna española y lengua materna no española.

Para alcanzar dicho punto de saturación y conseguir una caracterización significativa del tipo de alumno, relacionamos estas variables en categorías muestrales, donde se observa la diversidad propia del alumnado que asiste a los Centros de Adultos. Se destacan dos perfiles frecuentes: 10 alumnos menores de 23 años, en su gran mayoría no insertos en el mercado laboral y con lengua 
materna española; y 7 alumnos con una edad comprendida entre 23 y 48 años, hispanohablantes, que forman parte de la población activa con contrato laboral.

\subsection{Instrumentos}

Para vehicular el estudio de caso y recoger la información, se ha diseñado y aplicado una intervención didáctica (curso lectivo 2019-2020) adaptada a la educación de adultos y testada en trabajos anteriores (López-Bajo y Martínez-Rodríguez., 2019). La metodología didáctica aplicada está diferenciada en función de las dos grandes categorías de análisis que trabajamos: competencias de pensamiento histórico y competencias de conciencia histórica.

En relación a las competencias de pensamiento histórico, las evidencias se extraen de la metodología ordinaria del curso, basada en unos proyectos de investigación histórica denominados "casos históricos", que se explican en el siguiente epígrafe. La información se ha recogido en el aula a través de dos tipos de documentos evaluativos, que tienen como base las rúbricas de progreso competencial presentadas anteriormente: los trabajos resultantes de la resolución del caso histórico y una prueba de evaluación escrita al final. Con el fin de registrar el progreso, la evaluación se ha realizado en tres momentos:

- Valoración competencial inicial (septiembre-octubre 2019): Unidad Didáctica Sociedad y población en las sociedades preindustriales, con actividades que trabajan casos históricos parciales como "Peste Negra" o "Ascenso Social de la Familia Fugger".

- Valoración competencial intermedia (noviembre-diciembre 2019): Unidad Didáctica Política en la Edad Moderna (siglo XV-XVIII): Consolidación del poder monárquico y Estado moderno con la implementación completa del caso histórico: "Crónica sobre el conflicto de los comuneros".

- Valoración competencial final (enero-febrero 2020): Unidad Didáctica del segundo trimestre Transformaciones políticas en la Edad Contemporánea. Revoluciones siglo XVIIIXIX donde se encuadra el caso histórico del "Juicio a Luis XVI".

Por lo que respecta a las competencias de conciencia histórica, se ha elaborado una intervención didáctica ad hoc para esta investigación ${ }^{3}$, que evaluamos a través de una serie de preguntas (expuestas en el siguiente apartado "diseño de intervención en el aula") diseñadas a tal efecto con base en las rúbricas de progreso competencial presentadas anteriormente (Tablas 1, 2 y 3). También a través de tres momentos de aplicación, que desarrollaremos más concretamente en el siguiente epígrafe:

- Valoración competencial inicial: preguntas en el caso histórico parcial "Peste Negra" (septiembre-octubre 2019).

\footnotetext{
3 A diferencia de los "casos históricos", que pretenden una mejora y adquisición de competencias de pensamiento histórico y conllevan diferentes estrategias metodológicas estructuradas en diferentes sesiones, las actividades creadas para fomentar las competencias de conciencia histórica no tienen un desarrollo metodológico curricular, se centran en estimular respuestas fundamentadas y singulares de los alumnos sobre los temas propuestos con el fin de obtener una función valorativa para los propósitos de esta investigación.
} 
- Valoración competencial intermedia: preguntas en la sesión introductoria del caso histórico sobre "Condiciones laborales de los obreros en el siglo XIX" (marzo de 2020).

- Valoración competencial final: actividad final de curso en mayo 2020 con metodología online, debido a las circunstancias provocadas por la crisis sanitaria del Covid 19, denominada "La influencia de las epidemias en la historia: estudio histórico comparativo Peste negra (Edad Media 1348); Gripe española (1918) y Covid 19 (2020)".

\subsection{Diseño de intervención en el aula}

En la propuesta didáctica para el desarrollo de competencias de pensamiento histórico, implementamos una metodología ordinaria adaptada a la educación de adultos que busca simular la tarea del historiador (López-Facal et al., 2017) en miniproyectos de investigación histórica que trabajan el tiempo breve, denominados "casos históricos". Esta metodología, inserta en un proyecto de tesis doctoral, ya tiene un amplio recorrido empírico con varios cursos lectivos de pilotaje (2016-2019), en los que se han ido perfeccionando y puliendo los aspectos metodológicos adaptados al alumnado adulto, donde siempre hay que mantener un difícil equilibrio entre la continua intervención docente y el reto de fomentar la autonomía (SánchezDomenech, 2015).

Esta metodología permite poner en práctica los metaconceptos (Seixas y Morton, 2013) y las competencias asociadas que utiliza el historiador en su trabajo y nos permite desarrollar la adquisición de competencias de pensamiento histórico en el alumno. Por un lado, para analizar fuentes, obtener pruebas o evidencias históricas, el alumno debe disponer y analizar una selección de fuentes escogidas, que documenten aspectos concretos del hecho histórico en tiempo breve (Domínguez, 2015), y, finalmente, como representación, deben reconstruir un texto a modo de ensayo donde se plasme un relato interpretativo coherente y referenciado (Plá, 2015). Por otro lado, para los metaconceptos explicativos (cambio y continuidad o causa y consecuencia) la propuesta metodológica contiene una segunda dimensión que fomenta la explicación histórica desde la lógica de escalas temporales que propone el historiador Braudel (1970). De esta manera, el caso histórico está inserto en una unidad didáctica donde priman los procesos de tiempo largo. Consecuentemente, el modelo aplicativo tiene la finalidad de que el alumnado relacione de forma causal o inferencial un acontecimiento en tiempo corto, reconstruido a partir de las fuentes (caso histórico), con una dinámica de tiempo largo explicada previamente a modo de contexto general.

Por lo que respecta al desarrollo y valoración de las competencias de conciencia histórica, no implementaremos una metodología específica, usaremos la propia del caso histórico, pero con nuevas actividades, diseñadas para obtener evidencias de adquisición y desarrollo competencial, basadas en estrategias que han sido validadas en otros trabajos empíricos. Es por ello que se han implementado las estrategias y actividades que se señalan a continuación, incorporadas en la metodología ordinaria en diferentes "casos históricos".

Para la actividad inicial sobre la Peste negra se utiliza la estrategia de problematizar el pasado y conectarlo con el presente (Pages, 2019), con preguntas como "icrees que fue suficiente un acontecimiento como la Peste Negra para la transformación de una sociedad?, ¿̇estas transformaciones pueden llegar al presente?, ¿̇esta epidemia puede detener el desarrollo 
humano?, ¿̇se te ocurre algún acontecimiento que lo pueda hacer?" La intención es saber la capacidad que tiene el alumno de razonar y especular con un pasado lejano y sus implicaciones en el presente y en un escenario futuro, valorando los posibles sesgos de pensamiento histórico que pudiera tener.

Para la actividad intermedia "¿Por qué en nuestra sociedad existe desigualdad económica?", utilizaremos el enfoque de Martin Lücke (2012) que pretende conocer el origen de cualquier desigualdad utilizando indicadores estructurales de Pandel (relaciones de poder, diferencias en la propiedad de los medios de producción). La actividad tiene el fin de orientación de la experiencia futura $y$, a su vez, una pretensión de estimular las competencias de experiencia e interpretación con preguntas como: "¿Piensas que siempre fue igual (la desigualdad) en todas las épocas de la historia?, ¿dónde crees que está el origen de esta desigualdad en el sistema actual?", que pretenden relacionar las desigualdades económicas actuales en un contexto histórico más amplio.

En la actividad final "La influencia de las epidemias en la historia: estudio histórico comparativo Peste negra (Edad Media 1348); Gripe española 1918 y Covid 19 (2020)" se utilizarán estrategias comparativas de conflictos o sucesos alejados en el tiempo, en estructuras temporales diferentes (Pages, 2019; Rüsen, 2008) y estrategias de imaginar el futuro desde un enfoque diacrónico y temático. Se pretende así, trabajar en diferente medida las tres competencias de conciencia histórica propuestas. En primer lugar, la experiencia, con preguntas como: "los remedios - medidas contra la pandemia usados en la Peste negra medieval, isirven para luchar contra el Covid 19?, con la finalidad de saber si el alumno es capaz de usar su conocimiento del pasado para interpretar de forma compleja el presente. En segundo lugar, la interpretación del presente histórico (Covid 19), en una escala histórica más amplia desde la comprensión del cambio y la continuidad histórica, con preguntas como: "ìhemos avanzado mucho los seres humanos desde la Edad Media en relación a la lucha contra las epidemias?", "según lo que has visto de las otras epidemias anteriores, ¿̇piensas que habrá nuevas oleadas del Covid19?", "iestaremos mejor preparados?". Y finalmente, la orientación, que busca imaginar escenarios futuros probables teniendo en cuenta los sucesos del pasado y del presente histórico con preguntas como: "icómo será la nueva economía?, ¿̇cambiarán radicalmente las formas de vida?, ¿̇los cambios serán a peor? ¿̇nos mejorarán como persona?, ¿̇volveremos a vivir como antes del 2020?".

\section{Resultados}

El estudio de las narrativas seleccionadas de los 17 estudiantes adultos nos ofrece una rica fuente de información cualitativa para analizar, de una forma comparativa, el desarrollo de competencias de conciencia y pensamiento histórico a lo largo de la intervención didáctica que duró un curso lectivo. Pero, en síntesis, podemos avanzar que, de acuerdo con la premisa principal del trabajo, 9 de los 17 alumnos (un 53\%) han demostrado un desarrollo competencial en conciencia histórica, habiendo demostrado igualmente un progreso o bien un nivel alto de pensamiento histórico.

Las narrativas obtenidas en la experiencia nos han confirmado una visión compleja sobre la relación de competencias y pensamiento histórico en el desarrollo formativo del alumnado adulto. Hemos sintetizado dicha complejidad mediante una escala de valoración que clasifica a los 
estudiantes en relación con los resultados obtenidos en las categorías de análisis diseñadas, permitiéndonos distinguir cuatro grupos diferenciados.

Grupo 1. Alumnos que han demostrado alta capacitación de pensamiento histórico nivel III y demuestran, a su vez, un nivel complejo de conciencia histórica (nivel III) o bien, en ambas competencias, lo poseen desde el inicio de curso: 6 alumnos.

A modo de ejemplo, exponemos a continuación dos casos significativos que explican el cambio y la transformación social, usando conceptos históricos contextualizados y razonando sobre lo que permanece y lo que cambia.

En relación con las competencias de pensamiento histórico, durante la prueba de evaluación de la competencia inicial (octubre 2019), el alumno P.L.A. utiliza un texto del siglo X, donde el monje Adalberon describe los órdenes de la sociedad estamental, y responde a las preguntas "icuáles fueron las razones del cambio de sociedad?, ¿qué grupo social fue el protagonista de estos cambios?", de la siguiente manera

[P.L.A.19] En lo social [...] la élite social pasa de la aristocracia a la burguesía [...] la principal fuente de riqueza pasa de la tierra al capital [...] El grupo social fue la burguesía, que no disponía de privilegios ni toma de decisiones de gobierno.

Este razonamiento, que en el texto original posee una mayor complejidad con referencias al texto de Adalberon, evidencia por parte del estudiante un razonamiento histórico complejo de base. Presenta un dominio de los conceptos en la explicación causal en los que tiene en cuenta los cambios y los actores históricos de unas transformaciones de tiempo largo, que explican la sociedad de la Edad Contemporánea.

Esta complejidad también se puede apreciar en la respuesta de la alumna C.G.S. (19 años), aunque con un enfoque diferente. La estudiante señala otras causas de naturaleza demográfica y económica, quizás influida por la actividad realizada sobre la Peste, pero, al igual que el alumno anterior, demuestra dominio en la explicación en tiempo largo, como se muestra en la siguiente argumentación del cambio social a partir del texto de Adalberon:

[C.G.S.19] Las razones del cambio fueron las epidemias, que dejaron despobladas las zonas rurales al hacer que muchas personas se mudaran a la ciudad. Pero debido a todas las vacantes libres que había allí [...], este proceso culminó en la Revolución Industrial [...] El protagonista social fue la nobleza que tenía dinero y lo invirtieron después.

Los dos estudiantes mantienen una coherencia de progreso competencial en pensamiento histórico en las pruebas intermedias y finales con un nivel II (Tabla 5).

Tabla 5

Indicadores alcanzados por los estudiantes del Grupo 1

\begin{tabular}{|c|c|c|c|}
\hline \multirow[t]{3}{*}{ Alumnos } & \multirow{2}{*}{$\begin{array}{l}\text { Indicadores en } \\
\text { pensamiento histórico }\end{array}$} & \multicolumn{2}{|l|}{ Indicadores en conciencia histórica } \\
\hline & & Interpretación & Orientación \\
\hline & Indicador(nivel) & Indicador(nivel) & Indicador(nivel) \\
\hline
\end{tabular}




\begin{tabular}{|c|c|c|c|c|}
\hline M.A.A. (48 años) & $\begin{array}{l}1.1(\mathrm{II}) ; 1.2(\mathrm{II}) ; 2.1(\mathrm{III}) ; \\
3.1(\mathrm{III}) ; 3.2(\mathrm{III}) ; \\
3.3(\mathrm{III}) ; 3.4(\mathrm{III})\end{array}$ & $1.1(\mathrm{II}) ; 1.2$ (II) & 2.1 (III); 2.2 (III) & $\begin{array}{l}3.1 \text { (III);3.2(III); } \\
3.3 \text { (III) }\end{array}$ \\
\hline P.L.A(19 años) & $\begin{array}{l}1.1 \text { (III); } 1.2 \text { (III); } 2.1 \text { (III); } \\
3.1 \text { (III);3.2(III) } \\
3.3 \text { (III); } 3.4 \text { (III) }\end{array}$ & 1.1 (III);1.2 (III) & 2.1 (III); $2.2(\mathrm{III})$ & $\begin{array}{l}3.1 \text { (III);3.2(III); } \\
3.3 \text { (III) }\end{array}$ \\
\hline C.G.S. (18 años) & $\begin{array}{l}1.1(\text { III); } 1.2(\text { III); } 2.1 \text { (III); } \\
3.1(\text { III);3.2(III); } \\
3.3(\text { III); } 3.4(I I)\end{array}$ & 1.1 (III); $1.2(\mathrm{III})$ & 2.1 (III); 2.2 (III) & $\begin{array}{l}3.1 \text { (III); } 3.2 \text { (III); } \\
3.3 \text { (III) }\end{array}$ \\
\hline M.T.E. (22 años) & $\begin{array}{l}1.1 \text { (III); } 1.2(\mathrm{III}) ; 2.1 \text { (III); } \\
3.1 \text { (III);3.2(III) } \\
3.3(\mathrm{III}) ; 3.4(\mathrm{III})\end{array}$ & 1.1 (II); $1.2(\mathrm{II})$ & 2.1 (III); $2.2(\mathrm{III})$ & $\begin{array}{l}3.1 \text { (III); } 3.2(\text { (III); } \\
3.3 \text { (III) }\end{array}$ \\
\hline B.G.M (32 años) & $\begin{array}{l}1.1(\text { III); } 1.2(\text { III); } 2.1 \text { (III); } \\
3.1 \text { (III);3.2(III); } \\
3.3 \text { (III); } 3.4(\text { III) }\end{array}$ & 1.1 (III); $1.2(\mathrm{III})$ & 2.1 (III); $2.2(\mathrm{III})$ & $\begin{array}{l}3.1 \text { (III); } 3.2 \text { (III); } \\
3.3 \text { (III) }\end{array}$ \\
\hline J.Z.Q. (19 años) & $\begin{array}{l}1.1(\mathrm{II}) ; 1.2(\mathrm{II}) ; 2.1 \text { (II); } \\
3.1(\mathrm{III}) ; 3.2(\mathrm{III}) ; \\
3.3(\mathrm{III}) ; 3.4(\mathrm{II})\end{array}$ & 1.1 (II); $1.2(\mathrm{II})$ & 2.1 (II); 2.2 (II) & $\begin{array}{l}3.1 \text { (III);3.2(III); } \\
3.3 \text { (III) }\end{array}$ \\
\hline
\end{tabular}

Fuente: elaboración propia a partir de los indicadores presentados en las tablas 1, 2, 3 y 4.

Este razonamiento complejo de pensamiento histórico, analizando las evidencias, se puede extrapolar a los ejercicios de conciencia histórica en los que también demuestran nivel III de media en todos los indicadores (Tabla 5) desde la evaluación inicial hasta la final, con una valoración compleja del pasado para interpretar el presente e hipotetizar un futuro contextualizado y posible.

Así, en relación con las competencias de conciencia histórica, en el caso de la evaluación final "La influencia de las epidemias en la historia: estudio histórico comparativo Peste negra (Edad Media 1348); Gripe española 1918 y Covid 19 (2020)" (mayo de 2020), ante la pregunta de si los remedios o medidas contra la pandemia usados en la Peste negra medieval sirven para luchar contra el Covid 19, las respuestas de estos estudiantes nos dan pistas sobre esta capacitación nivel III de media, pero también encontramos diferencias.

El alumno P.L.A hace un uso del pasado en el presente de una forma ejemplarizante (desde la concepción de Rüsen), en el sentido de que se apoya en dinámicas pasadas como modelos para interpretar el hecho actual o imaginar uno futuro, y lo hace con sistematicidad y criterio. Como vemos en su respuesta, el alumno demuestra mayor simplicidad en su argumentación cobijándose en ideas estereotipadas sobre el uso de la tecnología y no usa referentes históricos del pasado:

[P.L.A.19] En mi opinión, los avances son claros, pero tampoco tanto, se ha visto cómo una pandemia puede paralizar el mundo y la vida como la conocemos [...] Creo que los cambios que va a haber solo van a acelerar lo que ya estaba pasando. En mi opinión, creo que algunas cosas sí se van a acelerar, como el avance de las tecnologías a pasos más grandes aún, muchos avances tienen que ver con el control de la población y a mí personalmente no me gusta mucho que puedan tener acceso a toda nuestra vida tan fácilmente [...]. 
En cambio, la alumna C.G.S. utiliza un pasado concreto y lo compara con el presente, argumentando desde la distancia temporal y teniendo en cuenta los contextos históricos. Como se observa en su respuesta, demuestra un uso complejo y bien contextualizado del pasado (competencia de experiencia), quizás con algún sesgo de simplificación por falta de conocimientos históricos más profundos; así como un enfoque del presente histórico dinámico desde las problemáticas sociales, conectado con el pasado y el futuro (competencia de interpretación):

[C.G.S.19] Una de las medidas que se usaron contra la masiva propagación de la Peste Negra, ya que no se tenía cura, era la de aislar a los pacientes infectados durante un período de cuarenta días y hasta que no se consideraba que el paciente ya no era peligroso no se tenía contacto con él; también se aisló a gente no enferma para evitar que estos se infectasen. Esta medida también ha sido utilizada con el Covid19, puesto que es una enfermedad de fácil propagación y tampoco se tiene una vacuna... Otra consecuencia social han sido las rebeliones, aunque por distintos motivos. Con la Peste Negra el pueblo se reveló violentamente ya que la nobleza y el clero intentaron frenar la inmigración y anular las subidas de salarios, con el Covid 19 también ha habido varias rebeliones, aunque no de manera violenta. Por una parte, la sanidad, enfermeros/as y médicos/as han llevado a cabo alguna que otra manifestación, para pedir mejoras salariales.

Estos dos estudiantes comparten edad y han tenido una trayectoria escolar similar, con problemas de madurez tardía antes de ingresar en la educación de adultos, pero sin desconexión en su formación. Ambos muestran que sus razonamientos sobre procesos históricos a partir del trabajo sobre competencias de pensamiento histórico, que van ganando en complejidad a lo largo del curso, les estimula y ofrece recursos conceptuales y argumentales, tanto en el razonamiento sobre su presente histórico como en aquellas competencias que hemos desarrollado según la concepción de conciencia histórica.

Grupo 2. Alumnos que han progresado desde niveles más bajos a superiores en ambas competencias de pensamiento y conciencia histórica: 3 alumnos.

En este grupo categorizamos alumnos que han progresado de una forma normalizada en los dos conceptos, pensamiento y conciencia histórica (Tabla 6). Éste es un perfil de alumnado con una personalidad madura, que ha realizado un seguimiento curricular óptimo durante todo el curso.

Tabla 6

Indicadores alcanzados por los estudiantes del Grupo 2

\begin{tabular}{|c|c|c|c|c|}
\hline \multirow[t]{2}{*}{ Alumnos } & \multirow{2}{*}{$\begin{array}{l}\text { Indicadores en } \\
\text { pensamiento histórico } \\
\text { Indicador(nivel) }\end{array}$} & \multicolumn{3}{|c|}{ Indicadores en conciencia histórica } \\
\hline & & $\begin{array}{l}\text { Experiencia } \\
\text { Indicador(nivel) }\end{array}$ & $\begin{array}{l}\text { Interpretación } \\
\text { Indicador(nivel) }\end{array}$ & $\begin{array}{l}\text { Orientación } \\
\text { Indicador(nivel) }\end{array}$ \\
\hline I.R.M. (29 años) & $\begin{array}{l}\text { 1.1(II);1.2(II);2.1(III); } \\
3.1(I I) ; 3.2(I I I) ; \\
3.3(I I I) ; 3.4(I I)\end{array}$ & $1.1(\mathrm{III}) ; 1.2(\mathrm{III})$ & $2.1(\mathrm{III}) ; 2.2(\mathrm{III})$ & $\begin{array}{l}3.1(I I I) ; 3.2(I I I) ; \\
3.3 \text { (III) }\end{array}$ \\
\hline M.C.F.(27 años & $\begin{array}{l}\text { 1.1(II);1.2(II);2.1(II); } \\
3.1(I I) ; 3.2(I I) \\
3.3(I I) ; 3.4(I I)\end{array}$ & $1.1(\mathrm{III}) ; 1.2(\mathrm{II})$ & $2.1(\mathrm{II}) ; 2.2(\mathrm{II})$ & $\begin{array}{l}3.1(I I) ; 3.2(I I) ; \\
3.3 \text { (II) }\end{array}$ \\
\hline
\end{tabular}




\begin{tabular}{lllll}
\hline V.G.G. (28 años) & $1.1($ II);1.2(II);2.1(II) & $1.1(\mathrm{III}) ; 1.2(\mathrm{II})$ & $2.1(\mathrm{II}) ; 2.2(\mathrm{II})$ & $3.1(\mathrm{II}) ; 3.2(\mathrm{II}) ;$ \\
& $; 3.1(\mathrm{II}) ; 3.2(\mathrm{II})$ & & $3.3(\mathrm{II})$ \\
& $3.3(\mathrm{II}) ; 3.4(\mathrm{II})$ & &
\end{tabular}

Fuente: elaboración propia a partir de los indicadores presentados en las tablas 1, 2, 3 y 4.

Como ejemplo representativo mostramos la evolución del alumno V.G.G. de 28 años. En la evaluación 0 de dichos conceptos, el alumno muestra un razonamiento muy simplificado con algún sesgo marcado. En el caso del pensamiento histórico, para explicar el cambio social entre la Edad Moderna y Contemporánea a través del texto de Adalberon, el alumno simplifica la causalidad en la intencionalidad de los agentes sociales explicando que: en la sociedad estamental mandaban los nobles [...] y en la sociedad de clases los burgueses (Nivel I de media). En el caso de la conciencia histórica, en la evaluación 0 , también observamos que, bajo una visión pesimista del desarrollo histórico, se denota cierta simplificación y sesgos de anacronía a la hora de explicar la desigualdad en la historia. Esta, desde el punto de vista del alumno, es debida siempre a las circunstancias socioeconómicas de la persona al nacer desde "la época de la esclavitud hasta ahora mismo" (V.G.G. 28 años, Nivel I de media inicial).

Sin embargo, en las evaluaciones finales (Tabla 6), tanto en las competencias valoradas de pensamiento como de conciencia, el alumno, al igual que el resto de estudiantes en este nivel, demuestra una mayor reflexión y complejidad en su argumentación, alcanzando niveles entre II y III de pensamiento y conciencia. Para explicar las transformaciones provocadas por la Revolución Francesa, el alumno razona en tiempo largo: a lo largo del siglo XIX se consolida las ideas de la revolución en dos ideologías que se denominan: liberalismo y nacionalismo (V.G.G. 28 años). En el ejercicio final de conciencia histórica que compara los remedios en la época de la Peste Negra con los actuales del Covid 19, el alumno identifica el cambio y continuidad histórica con una respuesta clara, aunque sin profundizar en la contextualización de ambas épocas.

[V.G.G.28] Las medidas en principio son las mismas. Aislar a las personas infectadas y pasar el periodo de cuarentena. Si el covid 19 fuese una bacteria como lo era la peste la solución a día de hoy sería más fácil, tomar antibiótico y listo, pero al ser un virus necesitamos vacunas y eso tarda más tiempo en desarrollarse.

Grupo 3. Alumnos que han progresado en pensamiento histórico, pero no en conciencia histórica: 1 alumno.

En la categoría tres encontramos al alumno R.G.S., que presenta una discordancia con el resto de alumnos analizados. En él se observa una mejoría significativa en competencias de pensamiento histórico a lo largo del curso, como se muestra, por ejemplo, en una respuesta compleja sobre trascendencia histórica, donde valora el cambio histórico producido por las ideas de la Revolución Francesa. En la respuesta, el estudiante distingue con clarividencia continuidades y permanencias usando cronología histórica, alcanzando Nivel III, tal como se observa en la Tabla 7. Pero, en cambio, en las preguntas relacionadas con conciencia histórica, mantiene los sesgos históricos de "conciencia no reflejada" en los ejercicios finales, donde muestra una clara limitación argumentativa que, además, es apoyada con hechos históricos tergiversados y estereotipados.

\section{Tabla 7}

Indicadores alcanzados por los estudiantes del Grupo 3

Alumnos Indicadores en conciencia histórica




\begin{tabular}{lllll}
\hline & $\begin{array}{l}\text { Indicadores en } \\
\text { pensamiento histórico } \\
\text { Indicador(nivel) }\end{array}$ & $\begin{array}{l}\text { Experiencia } \\
\text { Indicador(nivel) }\end{array}$ & $\begin{array}{l}\text { Interpretación } \\
\text { Indicador(nivel) }\end{array}$ & $\begin{array}{l}\text { Orientación } \\
\text { Indicador(nivel) }\end{array}$ \\
\hline R.G.S. (18 años) & $\begin{array}{l}\text { I.1(II);1.2(II);2.1(III); } \\
\text { 3.1(III);3.2(III) }\end{array}$ & $1.1(\mathrm{I}) ; 1.2(\mathrm{I})$ & $2.1(\mathrm{II}) ; 2.2(\mathrm{II})$ & $3.1(\mathrm{II}) ; 3.2(\mathrm{I}) ;$ \\
& $3.3(\mathrm{III}) ; 3.4(\mathrm{III})$ & & $3.3(\mathrm{I})$ \\
\hline
\end{tabular}

Fuente: elaboración propia a partir de los indicadores presentados en las tablas 1, 2, 3 y 4.

En la actividad de valoración final sobre pensamiento histórico (febrero 2019), dentro de la UD Transformaciones políticas en la Edad Contemporánea. Revoluciones siglo XVIII-XIX, ante la pregunta "Explica la trascendencia de la Revolución Francesa en los siguientes acontecimientos del siglo XIX", la respuesta fue la siguiente:

[R.G.S.18] Las ideas revolucionarias de 1789 no desaparecieron con la instauración de la monarquía absoluta en 1815, tras la dictadura expansionista de Napoleón, y son renovadas en 1830 con una revolución.

Así mismo, ante la pregunta de evaluación final de la conciencia histórica, "iLos remedios o medidas contra la pandemia usados en la Peste negra medieval sirven para luchar contra el Covid 19?", su respuesta fue:

[R.G.S.18] No, ya en la cuarentena por aquella época (Peste) solo se contemplaba aquellas embarcaciones las cuales contenían la plaga. $Y$ la medicina por aquella época era una "peste".

Como se observa en las dos respuestas, el alumno razona el conocimiento histórico de manera diferente. En la primera utiliza la información con rigor histórico utilizando cronología, actores históricos y ofrece una respuesta coherente al tiempo largo. En cambio, en la segunda respuesta demuestra improvisación y falta de rigor histórico en sus afirmaciones. Quizás la explicación a esta desigualdad es que en la actividad de pensamiento histórico el alumno se apoya en un conocimiento más estructurado que ha estudiado y reflexionado previamente, mientras que en la actividad que busca estimular conciencia histórica, el alumno no tiene este anclaje y resuelve con subjetividad aflorando de esta manera los sesgos propios de la conciencia no reflejada.

Grupo 4. Alumnos que no han progresado en ambas competencias a lo largo del curso (mantienen el nivel de la evaluación inicial entre I/II): 7 alumnos.

En el grupo cuatro encuadramos 7 alumnos que no han progresado en ambas competencias 0 bien han progresado de una forma muy leve, quedándose en niveles entre I y II de media (Tabla 8). Estos alumnos, aunque han seguido una trayectoria ascendente y han trabajado de forma laboriosa a lo largo del curso, mantienen sesgos en el pensamiento histórico, principalmente en las competencias 2 y 3 que priman el razonamiento causal y temporal. Estas deficiencias se observan con otros matices en el razonamiento de la conciencia histórica, principalmente la que hace referencia a la "experiencia" o uso del pasado histórico para interpretar hechos presentes.

Tabla 8

Indicadores alcanzados por los estudiantes del Grupo 4

Alumnos Indicadores en conciencia histórica




\begin{tabular}{|c|c|c|c|c|}
\hline & $\begin{array}{l}\text { Indicadores en } \\
\text { pensamiento histórico } \\
\text { Indicador(nivel) }\end{array}$ & $\begin{array}{l}\text { Experiencia } \\
\text { Indicador(nivel) }\end{array}$ & $\begin{array}{l}\text { Interpretación } \\
\text { Indicador(nivel) }\end{array}$ & $\begin{array}{l}\text { Orientación } \\
\text { Indicador(nivel) }\end{array}$ \\
\hline D.C.Q (20 años) & $\begin{array}{l}\text { 1.1(I);1.2(I);2.1(II); } \\
3.1(I I) ; 3.2(I I) \\
3.3(I) ; 3.4(I)\end{array}$ & $1.1(\mathrm{I}) ; 1.2(\mathrm{I})$ & $2.1(\mathrm{I}) ; 2.2(\mathrm{I})$ & $\begin{array}{l}3.1(1) ; 3.2(I) ; \\
3.3(I)\end{array}$ \\
\hline I.L.S. (18 años) & $\begin{array}{l}1.1(\mathrm{I}) ; 1.2(\mathrm{I}) ; 2.1(\mathrm{II}) ; \\
3.1(\mathrm{II}) ; 3.2(\mathrm{II}) ; \\
3.3(\mathrm{II}) ; 3.4(\mathrm{II})\end{array}$ & $1.1(\mathrm{I}) ; 1.2(\mathrm{I})$ & $2.1(I) ; 2.2(I I)$ & $\begin{array}{l}3.1(1) ; 3.2(1) ; 3.3 \\
\text { (I) }\end{array}$ \\
\hline A.Y.A.(18 años) & $\begin{array}{l}1.1(I I) ; 1.2(I I) ; 2.1(I I) ; \\
3.1(I I) ; 3.2(I I) \\
3.3(I I) ; 3.4(I I)\end{array}$ & $1.1(\mathrm{II}) ; 1.2$ (II) & $2.1(\mathrm{II}) ; 2.2(\mathrm{II})$ & $\begin{array}{l}3.1(\mathrm{II}) ; 3.2(\mathrm{II}) \text {; } \\
3.3(\mathrm{II})\end{array}$ \\
\hline A.U.G. (20 años) & $\begin{array}{l}1.1(I) ; 1.2(I) ; 2.1(I) ; \\
3.1(I I) ; 3.2(I I) \\
3.3(I) ; 3.4(I)\end{array}$ & $1.1(\mathrm{I}) ; 1.2(\mathrm{I})$ & $2.1(\mathrm{I}) ; 2.2(\mathrm{I})$ & $\begin{array}{l}3.1(1) ; 3.2(1) ; \\
3.3(1)\end{array}$ \\
\hline V.S.A.(19 años) & $\begin{array}{l}\text { 1.1(II);1.2(II);2.1(III); } \\
3.1(\mathrm{II}) ; 3.2(\mathrm{II}) \\
3.3(\mathrm{I}) ; 3.4(\mathrm{I})\end{array}$ & 1. (II); $1.2(I I)$ & $2.1(\mathrm{I}) ; 2.2(\mathrm{I})$ & $\begin{array}{l}3.1(1) ; 3.2(1) \\
3.3(1)\end{array}$ \\
\hline D.C.G. (24 años) & $\begin{array}{l}\text { 1.1(II);1.2(II);2.1(II); } \\
3.1(I I) ; 3.2(I I) ; \\
3.3(I) ; 3.4(I)\end{array}$ & $1.1(\mathrm{I}) ; 1.2(\mathrm{I})$ & $2.1(\mathrm{II}) ; 2.2(\mathrm{II})$ & $\begin{array}{l}3.1(I) ; 3.2(I) ; 3.3 \\
\text { (I) }\end{array}$ \\
\hline M.P.S. (38 años) & $\begin{array}{l}\text { 1.1(II);1.2(II);2.1(II); } \\
3.1(\mathrm{I}) ; 3.2(\mathrm{I}) ; 3.3(\mathrm{I}) ; 3.4(\mathrm{I})\end{array}$ & 1.1 (II); 1.2 (II) & $2.1(\mathrm{I}) ; 2.2(\mathrm{I})$ & $\begin{array}{l}3.1(1) ; 3.2(1) ; 3.3 \\
\text { (I) }\end{array}$ \\
\hline
\end{tabular}

Fuente: elaboración propia a partir de los indicadores presentados en las tablas 1, 2, 3 y 4 .

Exponemos, como ejemplo, dos alumnos: D.C.G. e I.LS. En pensamiento histórico, ambos casos demuestran un simplismo monocausal en una respuesta que requiere una argumentación compleja y que busca referentes históricos, trabajados de forma teórica en clase, con los que fundamentar la respuesta. Así, en la prueba de la valoración final (febrero 2019) dentro de la UD Transformaciones políticas en la Edad Contemporánea. Revoluciones siglo XVIII-XIX, ante el problema "Consecuencias de la Revolución Francesa. ¿̇La Revolución cambió algo?", responden:

[D.C.G.24] La Revolución Francesa provocará una transformación en la sociedad, los resultados no se manifestarán al final de la misma.

[I.L.S.18] Provocará una transformación en la sociedad europea y así comienza la Edad Contemporánea.

En relación con la conciencia histórica, la valoración competencial intermedia (marzo 2020), en la pregunta 2 "¿Piensas que siempre fue igual (la desigualdad) en todas las épocas de la historia? ¿Dónde crees que está el origen de esta desigualdad en el sistema actual?", en ambas respuestas predominan sesgos históricos del nivel I de la Conciencia "no reflejada", como presentismo/ahistoricismo y cierta idealización estereotipada, porque se argumenta a partir de actitudes como "los intereses" egoístas y personales, sin profundizar en factores económicos y 
sociales, ni citar cronología alguna. También se citan actores históricos sin argumentación explicativa ni referencia al cambio histórico.

[I.L.S.18] Si, siempre ha habido gente rica desde que aparecieran los reyes o los burgueses. Todo empezó en la revolución Industrial

[D.C.G.24] Si, siempre ha habido mucha desigualdad por intereses personales. En mi opinión está en la falta de oportunidades a la hora de obtener esa educación

También, según vemos, nos encontramos respuestas muy simples $y$, en el caso de I.L.S., contradictorias, debido a que comienza la frase exponiendo que "siempre ha habido desigualdades económicas" e, inmediatamente después, escribe que "todo empezó con la Revolución Industrial". Es importante advertir que presuponemos un cierto conocimiento histórico y contextual, ya que esta actividad es precedida por la explicación de la UD de Revolución Industrial y Movimiento obrero y, por tanto, es factible que a los alumnos les suenen determinados conceptos históricos y tengan capacidad para profundizar en ellos.

\section{Discusión y conclusiones}

Los datos anteriores, obtenidos de la comparativa en la adquisición de competencias entre pensamiento y conciencia histórica, nos dejan un primer resultado general, clave para una implementación didáctica de la conciencia histórica. Aunque conciencia y pensamiento histórico sean dos dimensiones diferenciadas del aprendizaje, en el grupo de alumnos analizado se constata una relación directa en el desarrollo de ambos grupos competenciales. En 16 alumnos de 17 (94\%) encontramos esta correspondencia entre los dos discursos históricos, de pensamiento y conciencia, bien en caso de progreso o bien en el caso contrario. Solo en un alumno hemos evidenciado una discrepancia de progreso entre ambos.

En consecuencia, nuestro estudio avalaría nuestra primera premisa de partida, en el sentido de que la conciencia histórica y el pensamiento histórico son dos atributos diferentes dentro del conocimiento histórico, pero complementarios. Ambos forman parte de la línea epistemológica del conocimiento científico de la historia y eso nos permite trabajar sus competencias con estrategias metodológicas propias de dicha ciencia.

Esta premisa no tiene un consenso claro entre los autores que han intentado aplicar el concepto de conciencia histórica a la didáctica. Así, nos encontramos con el enfoque de Seixas y de la escuela canadiense, que diluye la conciencia histórica en los conceptos de segundo orden de pensamiento histórico (Seixas y Morton, 2013). Aunque Seixas singularice la conciencia histórica con unas características propias ligándola con la memoria, la ciudadanía y la educación histórica, en su proyecto educativo el profesor canadiense introduce los dos conceptos dentro del mismo discurso, considerando que ambos comparten procesos de interpretación del pasado.

Un segundo enfoque, que es el que seguimos en nuestra investigación, considera la conciencia histórica y el pensamiento histórico como dos conceptos diferentes pero relacionados. Duquette (2011), trata con profundidad esta cuestión desde la premisa de que conciencia histórica y pensamiento histórico son verdaderamente dos realidades distintas. Para la autora, con el pensamiento histórico se producen narrativas críticas per se, en las que se incluyen subjetividades y donde se tienen en cuenta diferentes puntos de vista. Mientras que con la conciencia histórica estas operaciones cambian, fundamentándose en el uso y consumo de narrativas para lograr una 
comprensión del presente, y evidenciando que estas no tienen por qué tener un carácter crítico, simplemente pueden responder a una adecuación a las necesidades y contingencias del individuo. Esta diferenciación en dos discursos diferentes dentro del conocimiento histórico, que conectan el pensamiento crítico con el pensamiento histórico, pero no necesariamente con la conciencia, porque en ésta influyen otras variables como la memoria, la identidad o las narrativas maestras, es constante en los autores que desarrollan modelos de progreso competencial (Duquette 2011; Kölbl y Konrad, 2015; Rüsen, 2008).

Por nuestra parte, hemos trabajado con esta diferenciación de base, pero constatando en los resultados que ambas categorías son complementarias. De forma que en los 9 alumnos que hemos observado niveles de progreso en ambas categorías se puede apreciar que usan capacidades cognitivas complejas similares. Tanto para analizar un acontecimiento histórico del pasado y uno del presente, como cuando se les pide que los relacionen e interpreten una realidad presente cotidiana o bien imaginen un escenario futuro.

Estos alumnos son capaces de hacer una explicación compleja y relacionada del cambio histórico, de interconectar factores causales e incluso de inferir causas y consecuencias. En este sentido, siguiendo la línea del historiador Prost (2016), quien declara que la concepción temporal moderna es producto de la historia, podemos afirmar que tanto la conciencia como el pensamiento histórico son dos discursos diferentes de dicha concepción temporal, pero que utilizan la cognición propia del conocimiento científico histórico, y del desarrollo de éste depende una adquisición exitosa de ambas.

Esta idea también quedaría avalada en el caso de aquellos alumnos, 7 en concreto, en los que predominan limitaciones importantes de pensamiento histórico, principalmente en cuestiones de razonamiento lógico-causal o temporal, pues también predominan en ellos importantes sesgos de un nivel de conciencia "no reflejada". Principalmente el simplismo monocausal, con relaciones explicativas simplistas o estereotipadas en las relaciones entre dimensiones temporales. También presentismo (o idealización del presente), anacronismos e irrelevancia del cambio histórico.

Por último, no podemos dejar de señalar al alumno donde se observa una discrepancia entre ambos progresos competenciales. Recordamos que este alumno progresa de una forma significativa durante todo el curso en los indicadores de pensamiento histórico. En cambio, sus competencias de conciencia histórica se ven lastradas por el predominio de sesgos de la conciencia no reflejada. Este caso daría la razón a la tesis de Duquette (2011) por la que la conciencia no reflejada se fundamenta en unas narrativas que provienen de la acción mediada, que no fomentan un pensamiento crítico, de manera que su resistencia es grande debido a que forman parte de un sistema de valores de la persona construido desde la infancia.

No obstante, si bien la conciencia no reflejada es resistente, ello no significa que la acción didáctica sea estéril en potenciar su desarrollo y mejora. $Y$ en la comprobación de esta idea se ha asentado nuestra segunda premisa: existe la posibilidad de progresar y adquirir competencias de conciencia histórica y, en consecuencia, es viable para una intervención didáctica curricular. En este sentido, el estudio que se presenta en este artículo se encuentra dentro de una tradición de estudios empíricos sobre pensamiento y conciencia histórica (Aguirre, 2014; Barca, 2013; Duquette 2011; Kölbl y Straub, 2001; Miguel-Revilla y Sánchez-Agustí, 2018b). Y, en la línea de estos trabajos empíricos citados, de los resultados de nuestro estudio, donde un $53 \%$ de los 
estudiantes mostraron un progreso en el desarrollo de la conciencia histórica, se desprende que existe un potencial de progreso en competencias de conciencia histórica $y$, por tanto, un nivel crítico y complejo relacionado con el pensamiento histórico. Ambas premisas sientan los fundamentos para una propuesta educativa, debido a que permiten un horizonte de progreso (conciencia no reflejada a conciencia crítica) y, consecuentemente, se le puede aplicar un plan evaluador (rúbrica con indicadores), tal y como se ha realizado en esta investigación.

\section{Reflexiones finales}

A lo largo de estas páginas hemos tratado los principales ingredientes educativos, metodología y evaluación, de toda propuesta curricular que tenga en cuenta conceptos de conciencia histórica. Sus conclusiones, permiten avanzar en la construcción de un proyecto curricular plausible con conceptos propios de la conciencia histórica que favorezca el pensamiento crítico con las capacidades y herramientas propias del conocimiento histórico. Conceptos que permiten introducir nuevos enfoques críticos en la enseñanza de la historia como: utilización del pasado para interpretar el presente (competencia de la experiencia); comprensión del presente dentro de un proceso histórico de tiempo largo (competencia de la interpretación); e imaginación de un futuro hipotético y contextualizado (competencias de la orientación). Además, y es importante resaltarlo, estos conceptos no se encuadran dentro de categorías volubles u opinables de memoria histórica, sino que forman parte de un corpus estructurado que proviene de la ciencia histórica, como se refleja en la rúbrica competencial creada para evaluar el progreso de las competencias de conciencia histórica.

\section{Agradecimientos y financiación}

Esta investigación ha sido realizada en un contexto natural de la Educación de Adultos de la Comunidad Autónoma de Madrid. Para ello se ha contado con el permiso y apoyo de la dirección del CEPA, así como con el conocimiento y consentimiento de los estudiantes que han participado, todos ellos mayores de edad. Los autores agradecen a la institución y a los estudiantes la colaboración prestada, sin la cual no hubiera sido posible la investigación. No se ha dispuesto de financiación específica para su desarrollo.

\section{Contribución específica de los autores}

En este artículo se difunden parte de los resultados de una investigación doctoral desarrollada por el primer firmante, Héctor López-Bajo, en su contexto habitual de desempeño docente, bajo la orientación, supervisión e implicación personal en su elaboración de los otros dos firmantes, codirectores de la tesis doctoral.

\section{Bibliografía}

Aguirre, M. C. (2014). Estudios educativos sobre la conciencia histórica: temas y problemas. Revista Internacional de Ciencias Humanas, 3(2), 25-33.

Barca, I. (2013). Conciencia histórica: pasado y presente en la perspectiva de los jóvenes en Portugal. Clío \& Asociados. La Historia Enseñada, 17, 16-26. https://doi.org/10.14409/cya.v1i17.4170. 
Belando-Montoro, M. R., Barros R. y Lampreia, F. (2020). Adult learning and education in Spain and Portugal: an interpretative study of doctoral theses (2006-2018). International Journal of Lifelong Education, 39(5-6), 51 1-527. DOI: 10.1080/02601370.2020.1817165

Bizquerra, A. R. (2014). Metodología de la investigación educativa. Editorial La Muralla.

Braudel, F. (1970). La Historia y Las Ciencias Sociales. Alianza Editorial.

Bury, J. (2009). La idea del progreso. Alianza Editorial.

Carretero, M., y Montanero, M. (2008). Enseñanza y aprendizaje de la historia: Aspectos cognitivos y culturales. Cultura y Educación, 20(2), 133-1 42.

Dilthey, W. (1978). Introducción a las ciencias del espíritu, Obras Completas, Vol.I. Fondo de Cultura Económica.

Domínguez, J. (2015). Pensamiento histórico y evaluación de competencias. Editorial Graó.

Duquette, C. (2011). Le rapport entre la pensée historique et la conscience historique. Élaboration d'un modèle d'interaction lors de l'apprentissage de l'histoire chez les élèves de cinquième secondaire des écoles francophones du Québec. Tesis Doctoral. Quebec: Université Laval.

Duquette, C. (2015). Relating Historical Consciousness to Historical Thinking Through Assess-ment. En K. Ercikan y P. Seixas (eds.), New Directions in Assessing Historical Thinking (pp. 51-63). Routledge.

Fernández, J.A. (2000). El redescubrimiento de la Educación Permanente. Educación XXI, 3, 21 -51.

Freire, P. (2015). Pedagogía del oprimido. Siglo XXI.

Gadamer, H. G. (2003). El problema de la conciencia histórica. Editorial Tecnos.

Jarvis, P. (2010). Adult education and lifelong learning: Theory and Practice (4th ed.). Routledge.

Kolb, D. A. (1984) Experiential learning: Experience as the source of learning and development. Prentice Hall.

Kolb, D. y Kolb, A. (2017). The Experiential Educator: Principles and Practices of Experiential Learning. EBLS Press.

Kölbl, C. y Konrad, L. (2015). Historical Consciousness in Germany: Concept, Implementation, Assessment. En K. Ercikan y P. Seixas (eds.), New Directions in Assessing Historical Thinking (pp. 17-28). Routledge.

Kölbl, C. y Straub, J. (2001). Historical Consciousness in Youth. Theoretical and Exemplary Empirical Analyses. Forum Qualitative Social Research, 2(3), art. 9. https://www.qualitativeresearch.net/index.php/fqs/article/view/904/1975

Koselleck, R. (1993). Futuro pasado. Para una semántica de los tiempos históricos. Editorial Paidós.

López Bajo, H. y Martínez-Rodríguez, R. (2019). El desarrollo de competencias históricas en la educación de adultos: una propuesta de intervención a través de proyectos de investigación histórica. En M. J. Hortas, A. Días y N. de Alba, Enseñar y aprender didáctica de las ciencias sociales: la formación del profesorado desde una perspectiva sociocrítica (pp. 90-101). AUPDCS-ESELX. 
López-Facal, R., Gómez, C. J., Miralles, P. y Prats, J. (2017). Educación histórica y desarrollo de competencias. Editorial Graó.

Lukacs, J. (1968). Conciencia histórica o el pasado recordado. Schocken Book.

Martínez-Rodríguez, R. y Sánchez-Agustí, M. (2018). La enseñanza de la historia reciente en la adquisición de competencias para una ciudadanía democrática. En C. Gómez y P. Miralles (eds.), La educación histórica ante el reto de las competencias. Editorial Octaedro.

Mezirow, J. (1991). Transformative dimensions of adult learning. Jossey-Bass

Miguel-Revilla, D. y Sánchez-Agustí, M. (2018a). Conciencia histórica y memoria colectiva: marcos de análisis para la educación histórica. Revista de Estudios Sociales, 65, 113-125. DOI: $10.7440 /$ res65.2018.10.

Miguel-Revilla, D. y Sánchez-Agustí, M. (2018b). Modelos de conciencia histórica en el alumnado de Educación Secundaria: tradición, simbología y contextualización en torno a los restos del franquismo. Panta Rei. Revista Digital de Ciencia y Didáctica de la Historia, 8, 119 -1 42. DOI: $10.6018 /$ pantarei/2018/6.

OCDE (2009). Habilidades y competencias del siglo XXI para los aprendices del nuevo milenio en los países de la OCDE. OECD Education Working Papers, 41, 1-17.

Pagès, J. (2019). Enseñar historia, educar la temporalidad, formar para el futuro. El Futuro Del Pasado, 10, 19-56.

Pagès, J. y Santisteban, A. (2008). Cambios y continuidades: aprender la temporalidad histórica. En M. A. Jara (coord.), Enseñanza de la Historia. Debates y Propuestas (pp. 91-127). UNCOMA.

Plá, S. (2005). Aprender a pensar históricamente. La escritura de la historia en el bachillerato. Editorial Plaza y Valdés.

Prost, A. (2016). Doce lecciones sobre Historia. Editorial Comares.

Ricoeur, P. (2010). La memoria, la historia, el olvido. Editorial Trotta.

Rüsen, J. (2008). History: Narration, Interpretation, Orientation. Berghahn Books.

Sánchez-Domenech, I. (2015). La Andragogía de Malcom Knowles: Teoría y Tecnología de la Educación de Adultos (tesis doctoral). Universidad Cardenal Herrera-CEU.

Santisteban, A. (2010). La formación en competencias de pensamiento histórico. Clío \& Asociados, $14,34-56$.

Seixas, P. (2017). Historical Consciousness and Historical Thinking. En M. Carretero, S. Berger y M. Grever (eds.), Palgrave Handbook of Research in Historical Culture and Education (pp. 59-72). Palgrave Macmillan.

Seixas, P. y Morton, T. (2013). The Big Six Historical Thinking Concepts. Nelson Ed.

Wineburg, S. (2001). Historical Thinking and Other Unnatural Acts: Charting the Future of Teaching the Past. Temple University Press. 


\section{Panta Rei}

PANTA REI es una revista digital de investigación orientada a la Historia y otras ciencias afines. Su principal objetivo es la transmisión del conocimiento científico, dando una oportunidad también a los jóvenes investigadores que quieren abrirse camino en el estudio de las ciencias humanas y sociales. Se compone de estudios originales relacionados con la disciplina histórica así como su didáctica y difusión. Las diferentes secciones que componen la revista son: artículos de investigación, entrevistas a profesionales, recensiones de monografías de actualidad y crónicas de congresos o eventos científicos relevantes.

Todos los artículos publicados son objeto de un proceso de revisión a cargo de un mínimo de dos evaluadores, que se consideran expertos en el ámbito temático del artículo propuesto. Nuestro deseo es poder ofrecer unos contenidos rigurosos, de calidad y de interés.

El CEPOAT (Centro de Estudios del Próximo Oriente y la Antigüedad Tardía de la Universidad de Murcia) es la institución encargada de la coordinación y gestión de la revista, desde donde anualmente se lanzará la convocatoria para aquellos que estén interesados en publicar sus trabajos, siempre relacionados con la Historia, Arqueología, Historia del Arte, Didáctica de las Ciencias Sociales, etc.

PANTA REI is a digital journal focused on History and other sciences related to it. Its main objective is the transmission of scientific knowledge by giving also an opportunity to young researchers who want to make their way in the study of human and social sciences. It is composed by original studies related to History, as well as its didactics and promotion. The different sections of this journal are: research articles, interviews to professionals, recensions on monographs about current issues and reports about congresses or relevant scientific events.

All the articles published are subject to a revision process carried out by a minimum of two reviewers who are considered to be experts in the field of the article proposed. Our wish is to offer rigorous contents with quality and being of interest to the reader.

CEPOAT (Centre of Studies of the Middle East and Late Antiquity of the University of Murcia) is the institution in charge of the coordination and management of this journal. This is the centre from where the call for papers will be launched for all the people interested in publishing their papers, always related to History, Archeology, Art History, Didactics of the Social Sciences, etc. 


\section{Normas de publicación}

El autor se compromete a enviar trabajos originales, que no se encuentren publicados en otras revistas ni en otros idiomas. Así mismo, el mismo artículo no podrá ser presentado en otras revistas mientras dure el proceso de evaluación.

\section{Envío y presentación de originales}

Los artículos se enviarán exclusivamente a través del correo electrónico a la dirección pantarei@um.es. Los textos serán enviados en formato DOC y las imágenes en formato JPEG o TIFF, y con un tamaño mínimo de 2000 px. Éstas no aparecerán incorporadas en el texto, sino enviadas en archivo aparte y correctamente numeradas según su posición en el texto. Junto al trabajo, se rellenará y enviará un documento aparte en el que se especifiquen los datos del autor siguiendo el modelo disponible en la página Web de la revista.

Para la redacción de los trabajos se tendrá en cuenta el Manual de la American Psychological Association, en su sexta edición. La extensión máxima de los trabajos será de 30 páginas. La tipografía será Arial 11, con interlineado sencillo y sin espacio alguno entre párrafos. El texto deberá ir justificado a ambos márgenes y sin sangría en los primeros párrafos. Los márgenes serán de 2,50 cm. En los casos en los que fuera necesario incorporar notas, éstas irán a pie de página, enumeradas consecutivamente, con tipografía Arial 10, interlineado sencillo y justificadas a ambos márgenes.

Una información más detallada se encuentra disponible en la página http://www.um.es/cepoat/pantarei.

\section{Proceso de valoración y evaluación}

Una vez recibidos los trabajos, la Revista realizará una primera valoración. Si el trabajo enviado se ajusta a las normas de presentación propuestas, la temática es coincidente con la línea editorial de la revista y posee la calidad científica necesaria, será remitido al consejo asesor para una primera evaluación. Si no es así en este primer paso se puede rechazar directamente los documentos que incumplan claramente la línea editorial.

Será el Consejo Asesor quien indique a la revista la originalidad, relevancia, estructura, redacción, aparato bibliográfico, etc. del trabajo enviado y, para ello, se designará a dos revisores expertos externos que evaluarán cada uno de los trabajos, que pueden formar parte (o no) de este Consejo Asesor. La selección de los revisores se ajustará a la temática y características metodológicas del trabajo. El nombre y filiación de los autores serán eliminados del trabajo para su revisión, así como los revisores actuarán de manera anónima y confidencial.

Los revisores deberán rellenar un informe de evaluación que centrará su atención en aspectos tales como características formales, originalidad y novedad de los trabajos, relevancia de las propuestas y los resultados, calidad metodológica y validez científica.

Una vez terminado el proceso se decidirá la aceptación o no de los mismos y su publicación en el número que sea pertinente, así como las modificaciones susceptibles de ser realizadas para su final publicación. Dicha notificación se enviará únicamente por correo electrónico, en un plazo máximo de seis meses. 


\section{Publishing rules}

The author is committed to submit original papers not having been published in other reviews or in other languages. In this way, it is not allowed for the same paper to be presented in other reviews during the evaluation process.

\section{Submission and presentation of originals}

The articles will be exclusively submitted by email to pantarei@um.es. The texts will be submitted in DOC format and the images in JPEG or TIFF format, and with a minimum size of 2000 px. Images will not be integrated in the text but sent in another file and properly numbered according to their position in the text. Attached to the paper, a document will be filled out and sent where the author's data will be specified following the model available on the website.

The sixth edition of the Manual of the American Psychological Association will be taken into account for the writing of the papers. The length of the papers must not exceed 30 pages. Typography will be Arial 11, with simple line spacing and no space between paragraphs. The text must be justified on both margins without indentation in the first paragraphs. Margins size will be $2.50 \mathrm{~cm}$. Where it could be necessary the incorporation of notes, they will be at the bottom of the page, consecutively numbered with typography Arial 10, simple line spacing and justified on both margins.

More detailed information is available on the website: http://www.um.es/cepoat/pantarei.

\section{Examination and assessment process}

The Journal will submit the papers to a first examination once received. If the paper follows the presentation guidelines, the subject agrees with the editorial line of this journal, and possess the scientific quality required, it will be sent to the advisory council for a first assessment. If not, the documents which clearly fail to complete the editorial line may be rejected straightaway in this first step.

The Advisory Council will indicate the originality, relevance, structure, writing, bibliography, etc. of the text to the journal; for this purpose, two outside experts will be designated to review the papers; these experts can be (or not) part of this Advisory Council. The selection of the experts will adjust to the subject and methodological characteristics of the paper. Name and affiliation of the author will be eliminated from the text for its review, in this way experts will act anonymously and confidentially.

The experts will fill out an assessment report which will focus on aspects such as formal characteristics, originality and novelty of the papers, relevance and results of the proposal, methodological quality and scientific validity.

Once the process is finished, the acceptance or not of the papers and its publication in the corresponding edition will be decided, as well as the modifications that may be done for its final publication. This notification will be sent by email within 6 months maximum. 


\section{cepoAt edit.um}

